Check for updates

Cite this: Environ. Sci.: Processes Impacts, 2020, 22, 1355

Received 4th February 2020 Accepted 14th April 2020

DOI: 10.1039/d0em00063a

rsc.li/espi

\section{Interactions of ferrous iron with clay mineral surfaces during sorption and subsequent oxidation $\uparrow$}

\author{
Natacha Van Groeningen, (D) a Laurel K. ThomasArrigo, (D) a James M. Byrne, (D) b \\ Andreas Kappler, (D) ${ }^{b}$ Iso Christl (D) *a and Ruben Kretzschmar (D) ${ }^{a}$
}

In submerged soils and sediments, clay minerals are often exposed to anoxic waters containing ferrous iron $\left(\mathrm{Fe}^{2+}\right)$. Here, we investigated the sorption of $\mathrm{Fe}^{2+}$ onto a synthetic montmorillonite (Syn-1) low in structural Fe $(<0.05 \mathrm{mmol}$ Fe per $\mathrm{kg})$ under anoxic conditions and the effects of subsequent oxidation. Samples were prepared at two Fe-loadings ( 0.05 and 0.5 mol Fe added per kg clay) and equilibrated for 1 and 30 days under anoxic conditions $\left(\mathrm{O}_{2}<0.1 \mathrm{ppm}\right)$, followed by exposure to ambient air. Iron solid-phase speciation and mineral identity was analysed by ${ }^{57} \mathrm{Fe}$ Mössbauer spectroscopy and synchrotron X-ray absorption spectroscopy (XAS). Mössbauer analyses showed that Fe(॥) was partially oxidized (14-100\% of total added $\mathrm{Fe}^{2+}$ ) upon sorption to Syn-1 under anoxic conditions. XAS results revealed that the added $\mathrm{Fe}^{2+}$ mainly formed precipitates (layered Fe minerals, Fe(III)-bearing clay minerals, ferrihydrite, and lepidocrocite) in different quantities depending on the Fe-loading. Exposing the suspensions to ambient air resulted in rapid and complete oxidation of sorbed Fe(II) and the formation of Fe(III)-phases (Fe(III)-bearing clay minerals, ferrihydrite, and lepidocrocite), demonstrating that the clay minerals were unable to protect ferrous Fe from oxidation, even when equilibrated 30 days under anoxic conditions prior to oxidation. Our findings clarify the role of clay minerals in the formation and stability of Fe-bearing solid phases during redox cycles in periodically anoxic environments.

Environmental significance

Clay minerals are considered major sorbents in soils and sediments. However, their significance for the redox cycling of iron is still unclear. Under anoxic conditions, elevated concentrations of dissolved ferrous iron are observed. We demonstrate that at circumneutral to alkaline $\mathrm{pH}$, surface-mediated oxidation of ferrous iron can occur under anoxic conditions in the presence of clays that are virtually free of structural iron. The retention of dissolved ferrous iron in the presence of clay minerals was evidenced to be mainly due to the formation of secondary Fe(II/II) phases. Subsequent aeration led to the complete oxidation of iron. In contrast to surface precipitation, adsorption of dissolved iron by layered aluminosilicates plays a minor role in iron retention and does not protect ferrous iron from oxidation.

\section{Introduction}

Iron is ubiquitous in soils and sediments and of great importance in the biogeochemical cycling of metals. ${ }^{\mathbf{1 - 5}}$ Its solubility in well-aerated soils is mainly controlled by the dissolution and

${ }^{a}$ Institute of Biogeochemistry and Pollutant Dynamics, Department of Environmental Systems Science, CHN, ETH Zürich, 8092 Zürich, Switzerland. E-mail: iso.christl@ env.ethz.ch

${ }^{b}$ Geomicrobiology Group, Centre for Applied Geosciences (ZAG), University of Tübingen, Hölderlinstrasse 12, D-72074, Tübingen, Germany

$\dagger$ Electronic supplementary information (ESI) available. Calculation of saturation indices, protocol to ensure anoxic conditions, measured $\mathrm{pH}$ after equilibration, percentage of $\mathrm{Fe}$ sorbed by oxidation of dissolved ferrous iron, concentration analyses, concentration of Si release analysis, details on XAS data collection and reduction, additional Mössbauer spectra and XAS results. See DOI: 10.1039/d0em00063a precipitation of $\mathrm{Fe}(\mathrm{III})$-(oxyhydr)oxides. ${ }^{6}$ During periods with anoxic conditions, Fe(III)-(oxyhydr)oxides serve as electron acceptors for dissimilatory metal-reducing bacteria leading to the release of aqueous $\mathrm{Fe}^{2+}$. Ferrous iron $\left(\mathrm{Fe}^{2+}\right)$, being one of the most abundant redox-active species in anoxic soils, has a crucial role in controlling macronutrient and trace element cycles. ${ }^{7}$ The retention of $\mathrm{Fe}^{2+}$ in soils and sediments is, as for most divalent cations, governed by sorption processes (including adsorption as well as surface precipitation and polymerization) ${ }^{8}$ to minerals with a large surface area and specific sorption properties such as clay minerals, carbonates, and Fe(III)- and Mn(Iv, III)-(oxyhydr)oxides. Under anoxic conditions, clay minerals are one of the most important sorbent phases as they are commonly found in high abundance in soils but are not susceptible to reductive dissolution. Aqueous $\mathrm{Fe}^{2+}$ can adsorb to clay mineral surfaces via cation exchange on permanently charged face 
surfaces, by the formation of surface complexes on edge surfaces, or by the formation of surface clusters and precipitates. $\mathrm{Fe}^{2+}$ is expected to effectively compete with some trace metal cations (e.g., $\mathrm{Zn}^{2+}, \mathrm{Cd}^{2+}$ ) for sorption sites on clay minerals, ${ }^{\mathbf{9}, 10}$ leading to mobilization of trace metals under anoxic conditions. On the other hand, immobilization of trace metals can occur through additional pathways such as incorporation into newly formed solids.

Natural clay minerals often contain Fe(II) and Fe(III) in their crystal lattice ${ }^{\mathbf{1 1}, \mathbf{1 2}}$ and it has been shown that electrons can be transferred from ferrous iron to structural Fe(III). ${ }^{13-18}$ Iron-free clay minerals are generally considered to be redox-inactive within the natural redox potential of soils. However, Géhin et al. ${ }^{14}$ demonstrated that under strictly anoxic conditions $\mathrm{Fe}$ (II) was oxidized to Fe(III) on surfaces of clay minerals having very low iron contents. Potential electron acceptors in low-iron clay minerals could include trace $\mathrm{Fe}(\mathrm{III})$ impurities, other redoxactive elements (e.g., Ti), or hydrogen. ${ }^{\mathbf{1 4}}$ Following oxidation, the hydrolysis of $\mathrm{Fe}(\mathrm{III})$ may lead to the formation of oxyhydroxide clusters or precipitates on the clay mineral surface, as has been observed by many studies. ${ }^{\mathbf{1 2 , 1 5 , 1 9 , 2 0}}$ However, uncertainties still prevail about the ability of Fe-free clay mineral to induce electron transfer from adsorbed $\mathrm{Fe}(\mathrm{II})$ to the clay mineral, leading to the formation of adsorbed Fe(III). ${ }^{19,21}$

When reduced soils are exposed to air, oxidation of sorbed $\mathrm{Fe}(\mathrm{II})$ by $\mathrm{O}_{2}$ is expected to occur, which may lead to the formation of polynuclear $\mathrm{Fe}(\mathrm{III})$-oxyhydroxide clusters and surface precipitates. These oxidation products can effectively immobilize trace elements by co-precipitation. ${ }^{22-26}$ The nature of the surface precipitates formed by oxidation of ferrous iron depends on the reaction conditions $(\mathrm{pH}$, rate of oxidation, suspension concentration, temperature, and concentration of impurities). ${ }^{27}$ However, if secondary Fe phases were formed first under anoxic conditions, the type of surface precipitates formed during oxidation could also be influenced by the solid phases formed in the absence of $\mathrm{O}_{2}$. It has been shown by Génin et al. ${ }^{28}$ that $\mathrm{Fe}(\mathrm{OH})_{2}$ oxidizes into chloride green rust (Cl-GR) and further oxidation of Cl-GR leads to the formation of lepidocrocite, goethite, or akaganeite, depending on the ratio of initial concentrations of $\mathrm{Cl}^{-}$and $\mathrm{OH}^{-}$. However, it has not been identified which Fe-bearing minerals form by oxidation of $\mathrm{Fe}$ (II) associated with clay mineral surfaces.

Since clay minerals are not susceptible to reductive dissolution, a large portion of the Fe pool in submerged soils is believed to be sorbed or incorporated into clay minerals. ${ }^{29}$ To date, few studies have been conducted on $\mathrm{Fe}^{2+}$ sorption on $\mathrm{Fe}-$ free clay minerals, ${ }^{\mathbf{1 4 , 2 1 , 3 0}}$ which allows the determination of $\mathrm{Fe}^{2+}$ adsorption on clay minerals and the relevance of this process for Fe retention. Furthermore, the effects of subsequent oxidation on the speciation of Fe sorbed onto clay surfaces have not yet been determined. Therefore, the aims of this study were to investigate the interactions of $\mathrm{Fe}^{2+}$ with a low structural iron montmorillonite under anoxic conditions, and to characterize the Fe surface species and secondary phases formed during sorption. Additionally, we investigated the Fe species formed by oxidation of Fe sorbed on the clay mineral surface. The results will improve our understanding of the role of clay minerals in $\mathrm{Fe}$ redox cycling and phase (trans-)formation.

\section{Experimental}

\section{Preparation of clay mineral}

A synthetic montmorillonite (Barasym SSM-100), referred to as Syn-1 was purchased from the Source Clays Repository of the Clay Minerals Society (Purdue University, West Lafayette, IN). Syn-1 is very low in structural Fe and was selected for this study to minimize potential oxidation of adsorbed $\mathrm{Fe}^{2+}$ by structural $\mathrm{Fe}(\mathrm{III})$. Syn-1, was size fractionated $(<2 \mu \mathrm{m})$, Ca saturated, and washed free of excess salt. The size-fractionated Ca-saturated Syn-1 was analyzed both as oriented and random oriented powder samples by X-ray diffraction (XRD, D8 Advance, Bruker). Diffractograms were recorded in Bragg-Brentano geometry from 3 to $80^{\circ} 2 \theta$ with a step size of $0.02^{\circ} 2 \theta$ and $4 \mathrm{~s}$ acquisition time per step, using $\mathrm{Cu} \mathrm{K} \alpha$ radiation $(\lambda=1.5418 \AA$, $40 \mathrm{kV}$, and 40 $\mathrm{mA}$ ). X-ray fluorescence analysis (XRF, XEPOS, Spectro) was performed for elemental analysis of the clay mineral. The measured diffractograms showed trace amounts of boehmite $(\gamma-\mathrm{AlOOH})$ and total iron content was determined by XRF as $0.026 \mathrm{~g} \mathrm{~kg}^{-1}$. The specific surface area of Syn-1 was measured by multi-point $\mathrm{N}_{2}$-BET analysis (ASiQwin, Quantachrome) as $95 \pm$ $2 \mathrm{~m}^{2} \mathrm{~g}^{-1}$.

\section{Anoxic ferrous iron sorption experiments}

Batch sorption experiments were performed to quantify $\mathrm{Fe}^{2+}$ sorption on Ca-saturated Syn-1 as a function of pH (4-10) and $\mathrm{CaCl}_{2}$ concentration $\left(0.1,1.0\right.$, and $\left.10 \mathrm{mM} \mathrm{CaCl}_{2}\right)$ for two fixed ferrous iron concentrations $(0.05$ and $0.5 \mathrm{mM})$ at $25 \pm 1{ }^{\circ} \mathrm{C}$. The equilibration time was $24 \mathrm{~h}$ and the clay suspensions had a solid-to-solution ratio of $1 \mathrm{~g} \mathrm{~L}^{-1}$, giving $\mathrm{Fe} /$ clay ratios of 0.05 and $0.5 \mathrm{~mol}$ Fe per kg clay, respectively. Due to the high oxygen sensitivity of $\mathrm{Fe}^{2+}$, all batch sorption experiments were performed under anoxic conditions $\left(\mathrm{O}_{2}<0.1 \mathrm{ppm}\right)$. All solutions were prepared with $\mathrm{O}_{2}$ - and $\mathrm{CO}_{2}$-free, doubly deionized (DDI) water ( $\geq 18.2 \mathrm{M} \Omega \mathrm{cm}$, Milli-Q, Millipore, Merck KGaA, Darmstadt, Germany), which was produced by boiling the water while purging it with pure nitrogen gas for at least $3 \mathrm{~h}$ outside the glovebox. This was done to prevent oxidation of dissolved $\mathrm{Fe}^{2+}$ and avoid the formation of carbonate solids at alkaline $\mathrm{pH}$ values contributing to the removal of $\mathrm{Fe}^{2+}$ from solution. All batch experiments were prepared in an anoxic glovebox from a stock clay suspension $\left(25 \mathrm{~g}\right.$ clay $\left.\mathrm{L}^{-1}\right)$, which was preequilibrated under a $\mathrm{N}_{2}$ atmosphere in the glovebox for 7 days. Before starting the sorption experiments, clay suspensions were equilibrated for 1 hour at $\mathrm{pH} 5$ to remove $\mathrm{CO}_{2}$. Subsequently, aliquots of a $\mathrm{Fe}^{2+}$ stock solution (0.25 M made from a $\mathrm{FeCl}_{2}$ salt) were added to the clay suspension to obtain a total $\mathrm{Fe}^{2+}$ concentration of 0.05 and $0.5 \mathrm{mM}$. The suspension $\mathrm{pH}$ was adjusted by adding a pre-determined amount of $\mathrm{CO}_{2}$-free base ( 0.01 or $0.1 \mathrm{M} \mathrm{NaOH})$ to reach the target $\mathrm{pH}$ value.

The $\mathrm{pH}$ of the clay suspensions was measured for all samples at the end of the equilibration period. The samples were then passed through $0.22 \mu \mathrm{m}$ nylon filters (VWR International) and 
the filtrates were acidified. Acidified samples were analyzed for $\mathrm{Ca}, \mathrm{Al}, \mathrm{Si}, \mathrm{Zr}, \mathrm{V}$ and Fe by inductively coupled plasma-optical emission spectrometry (ICP-OES, Vista MPX, Varian) (Ca, Al, Si) or mass spectrometry (ICP-MS, 8800 QQQ-ICP-MS, Agilent) (Fe, $\mathrm{Zr}, \mathrm{V})$.

\section{Iron solid phase speciation}

Two set of samples were prepared to investigate the solid-phase speciation of $\mathrm{Fe}$ and the effects of equilibration time ( 1 and 30 days), $\mathrm{pH}$ (7 and 8), Fe-loading (0.05 and $0.5 \mathrm{~mol}$ Fe per kg clay), and oxidation. The first group of samples were prepared for ${ }^{57} \mathrm{Fe}$ Mössbauer spectroscopy and the second for XAS analysis. All batch sorption experiments were performed in $250 \mathrm{~mL}$ Nalgene ${ }^{\circledR}$ bottles and stirred at $800 \mathrm{rpm}$ for 1 or 30 days under anoxic conditions. After equilibration, aliquots of the suspensions were sampled and filtered for analysis of solutes by ICPOES or ICP-MS. For solid-phase analysis, $70 \mathrm{~mL}$ suspension was passed through a $0.22 \mu \mathrm{m}$ cellulose nitrate filter (GE Healthcare Life Sciences) and solids were collected. The collected solids were then washed with deoxygenated $\mathrm{CO}_{2}$-free DDI water and subsequently dried in the dark in the glovebox. From the remaining suspensions, $50 \mathrm{~mL}$ was transferred into $50 \mathrm{~mL}$ polypropylene (PP) centrifuge tubes. These PP centrifuge tubes were then taken out of the glovebox and opened, in order to exchange the remaining headspace $(\sim 5 \mathrm{~mL})$ with ambient air, before shaking them end-over-end for $24 \mathrm{~h}$. The solids of airexposed suspensions were filtered, washed, and dried under ambient air.

${ }^{57}$ Fe Mössbauer spectroscopy. Solid samples were prepared for ${ }^{57} \mathrm{Fe}$ Mössbauer spectroscopy by equilibrating Syn-1 $\left(\sim 1 \mathrm{~g} \mathrm{~L}^{-1}\right)$ for $24 \mathrm{~h}$ with an isotopically enriched ${ }^{57} \mathrm{Fe}^{2+}$ solution $(0.05$ and $0.5 \mathrm{mM})$ in $10 \mathrm{mM} \mathrm{CaCl}$. The enriched ${ }^{57} \mathrm{Fe}^{2+}$ solution had the following isotopic composition (in \% of total Fe): ${ }^{54} \mathrm{Fe}: 0.03,{ }^{56} \mathrm{Fe}: 2.95,{ }^{57} \mathrm{Fe}: 95.06,{ }^{58} \mathrm{Fe}: 1.96$ for the $0.05 \mathrm{mM}$ Fe solutions, and ${ }^{54} \mathrm{Fe}: 4.04,{ }^{56} \mathrm{Fe}: 82.92,{ }^{57} \mathrm{Fe}: 12.39,{ }^{58} \mathrm{Fe}: 0.65 \%$ for the $0.5 \mathrm{mM}$ Fe solutions, respectively. The enriched ${ }^{57} \mathrm{Fe}$ solutions were prepared from an ${ }^{57} \mathrm{Fe}$ stock solution made by dissolving ${ }^{57} \mathrm{Fe}$ metal powder $\left(95.06 \%{ }^{57} \mathrm{Fe}\right.$, Isoflex, San Francisco, CA) in $2 \mathrm{M} \mathrm{HCl}$ at $70{ }^{\circ} \mathrm{C}$ overnight, which was then purged with $\mathrm{N}_{2}(\mathrm{~g})$, sealed, and transferred to the glovebox. The Fe concentration of the ${ }^{57} \mathrm{Fe}(\mathrm{II})$ solution was determined in $0.22 \mu \mathrm{m}$ filtrates by ICP-OES.

The specificity of Mössbauer spectroscopy to ${ }^{57} \mathrm{Fe}$ was used to determine the oxidation states of $\mathrm{Fe}$ in the solid samples. Dried powders for Mössbauer analysis were loaded into Plexiglas holders $\left(1 \mathrm{~cm}^{2}\right)$ under anoxic conditions. The samples were placed in a closed-cycle He cryostat (SHI-850-I, Janis Research Co.) for measurement at $77 \mathrm{~K}$. Spectra were collected with a constant acceleration drive system (WissEl, Wissenschaftliche Elektronik $\mathrm{GmbH}$ ) in transmission mode with a ${ }^{57} \mathrm{Co} / \mathrm{Rh}$ source and calibrated against a $7 \mu \mathrm{m}$ thick $\alpha^{-57} \mathrm{Fe}$ foil measured at room temperature. For two selected samples, the temperature was varied between $77 \mathrm{~K}$ and $15 \mathrm{~K}$. All spectra were analyzed using the Recoil software ${ }^{\mathbf{3 1}}$ by applying a Voigt-based fitting routine. $^{32}$ The half-width at half maximum (HWHM) was fixed to a value of $0.130 \mathrm{~mm} \mathrm{~s}^{-1}$ for all samples.
X-ray absorption spectroscopy (XAS). The samples for XAS analysis were prepared by equilibrating Syn-1 $\left(\sim 5 \mathrm{~g} \mathrm{~L}^{-1}\right)$ with a $\mathrm{Fe}^{2+}$ solution $(0.25$ and $2.5 \mathrm{mM})$ in $50 \mathrm{mM} \mathrm{CaCl}_{2}$ to maintain similar conditions as in our previous experiments, but with higher solid concentrations suitable to facilitate XAS analysis. This set of samples was prepared to investigate the solid-phase speciation of $\mathrm{Fe}$ and the effects of equilibration time (1 and 30 days), $\mathrm{pH}(\sim 7$ and $\sim 8)$, Fe-loading (0.05 and $0.5 \mathrm{~mol} \mathrm{Fe} \mathrm{per} \mathrm{kg}$ clay), and oxidation.

X-ray absorption spectroscopy (XAS) at the Fe K-edge $(7112 \mathrm{eV})$ was conducted at the SAMBA beamline of SOLEIL (Saint-Aubin, France). The dried solids were homogenized, pressed into $13 \mathrm{~mm}$ pellets and sealed between Kapton ${ }^{\circledR}$ tape. For transport to the synchrotron, samples were sealed in two layers of gas-tight-aluminum foil under $\mathrm{N}_{2}$ gas. Two samples were additionally prepared as oriented clay films for polarizedXAS measurement $\left(\alpha=10^{\circ}, 35^{\circ}, 55^{\circ}\right.$, and $\left.80^{\circ}\right)$. The oriented samples were prepared by collecting the clay on a cellulose filter $(0.22 \mu \mathrm{m})$, separating the solid film from the filters, stacking the solid films, and sealing them between Kapton ${ }^{\circledR}$ tape. All measurements were conducted at $25 \mathrm{~K}$ to avoid beam damage and oxidation of oxygen-sensitive samples. Sample spectra were evaluated by linear combination fitting (LCF) to obtain information about the speciation of Fe and the formation of new Febearing solid-phases. Shell-fit analyses of the extended X-ray absorption fine structure (EXAFS) spectra were also performed to obtain information about the short range local coordination environment of Fe. The nature of the backscattering atoms around $\mathrm{Fe}$ in the sorption samples was assessed using Morlet wavelet transforms (WT) of $k^{3}$-weighted EXAFS data using the Fortran version of the HAMA software developed by Funke et al. ${ }^{33}$ Details on all measurements, data reduction, and analyses are provided as (ESI $\dagger$ ).

\section{Results and discussion}

\section{Sorption of ferrous iron to Syn-1}

The $\mathrm{pH}$-dependent sorption of $\mathrm{Fe}^{2+}$ to Syn-1 under anoxic conditions at different $\mathrm{CaCl}_{2}$ and $\mathrm{Fe}$ concentrations is shown in Fig. 1. At low $\mathrm{pH}(\sim 4)$, only small fractions of the total $\mathrm{Fe}^{2+}$ were sorbed to the clay, with the highest sorbed fraction in suspensions prepared with DDI water. This is consistent with nonspecific adsorption of $\mathrm{Fe}^{2+}$ to cation exchange sites of the clay mineral and sorption competition with $\mathrm{Ca}^{2+}$. Between $\mathrm{pH} 4$ and 7, sorption of $\mathrm{Fe}^{2+}$ increased strongly with $\mathrm{pH}$ and reached nearly $100 \%$ at circumneutral $\mathrm{pH}$ values. In the neutral to alkaline $\mathrm{pH}$ range, no clear sorption competition with $\mathrm{Ca}^{2+}$ was observed, pointing to inner-sphere surface complex formation of $\mathrm{Fe}^{2+}$ on clay mineral edge-surfaces and/or formation of surface clusters or precipitates. In all batch sorption experiments, the aqueous phase was thermodynamically undersaturated with respect to possible Fe-bearing solids at $\mathrm{pH}<8$ (see Table $\mathrm{S} 1 \dagger$ ), and hence, no secondary phases were expected to form by homogeneous nucleation and precipitation.

To investigate the sorption mechanism of $\mathrm{Fe}^{2+}$ to Syn- 1 by XAS further, an additional set of samples was prepared at $\mathrm{pH} 7$ or 8 under anoxic conditions containing $5 \mathrm{~g} \mathrm{~L}^{-1}$ clay, 0.25 or 

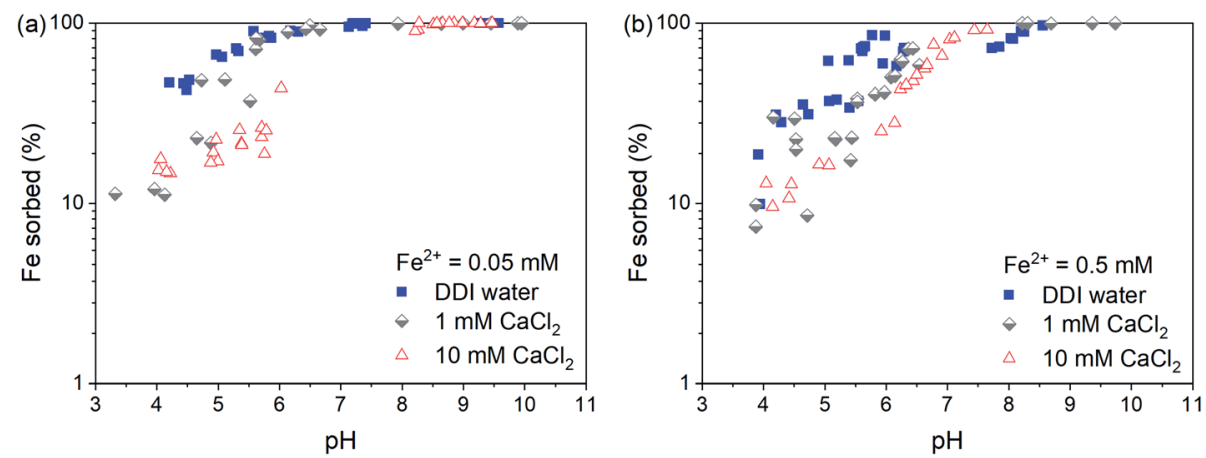

Fig. 1 Percentage of $\mathrm{Fe}^{2+}$ sorbed on Syn-1 $\left(\sim 1 \mathrm{~g} \mathrm{~L}^{-1}\right)$ as a function of $\mathrm{pH}$ at different $\mathrm{CaCl}_{2}$ concentrations. Samples in DDI water had a Ca ${ }^{2+}$ concentration of $\sim 0.1 \mathrm{mM}$ after 1 day equilibration. Total $\mathrm{Fe}^{2+}$ concentrations of (a) 0.05 and (b) $0.5 \mathrm{mM}$ were added and equilibrated for 1 day with $1 \mathrm{~g} \mathrm{~L}^{-1}$ Syn-1.

$2.5 \mathrm{mM} \mathrm{Fe}^{2+}$, and $50 \mathrm{mM} \mathrm{CaCl}_{2}$. The high $\mathrm{CaCl}_{2}$ concentration and $\mathrm{pH}$ values were selected to focus on sorption processes on edge surfaces, which are expected to dominate under these conditions. Furthermore, at $\mathrm{pH}<8$ the dissolved $\mathrm{Fe}^{2+}$ concentrations in the suspensions were always below saturation with respect to $\mathrm{Fe}(\mathrm{OH})_{2}$ (Table $\left.\mathrm{S} 1 \dagger\right)$.

In the XAS samples, the sorbed fraction of $\mathrm{Fe}^{2+}$ was higher at $\mathrm{pH} \sim 8$ than at $\mathrm{pH} \sim 7$ (Table $\mathrm{S} 2 \dagger$ ). The amount of sorbed $\mathrm{Fe}^{2+}$ also slightly increased with increasing equilibration time from day 1 to 30 (Table S2 and Fig. S3†), e.g., by 0.02 mol Fe per kg clay at $\mathrm{pH}$ 7. This observation is consistent with findings by Zhu et al. ${ }^{34}$ who observed an increase in $\mathrm{Fe}^{2+}$ sorption to Syn-1 during 5 days at $\mathrm{pH}$ 7.5. Such increases of $\mathrm{Fe}^{2+}$ sorption suggest that slow sorption processes were taking place. Possible mechanisms explaining slow sorption kinetics include dissolution and precipitation reactions on surfaces..$^{35-44}$

The derivative of the Fe K-edge XANES spectra of the solids from selected $\mathrm{Fe}^{2+}$ sorption samples are shown in Fig. 2, along with relevant $\mathrm{Fe}$ reference compounds for comparison. The position of the highest maximum in the derivatives of XANES spectra for the high Fe-loading anoxic sorption sample at $7125 \mathrm{eV}$ suggests an Fe oxidation state of close to +2 . However, the presence of a small shoulder at $7128 \mathrm{eV}$ might suggest that a small fraction of $\mathrm{Fe}^{2+}$ was oxidized in these samples. For the low Fe-loading anoxic sample at $\mathrm{pH} \sim 8$, the position of the highest maximum is consistent with a valence state between +2 and +3 , suggesting that sorbed $\mathrm{Fe}^{2+}$ was partially oxidized during sorption experiments. The low Fe-loading anoxic sample at pH 7 exhibited a maximum at $7127 \mathrm{eV}$, corresponding to a +3 oxidation state.

To quantify the oxidation states of sorbed Fe on Syn-1 under anoxic conditions with greater precision, Mössbauer spectroscopy was performed for selected solids $\left(1 \mathrm{~g} \mathrm{~L}^{-1}\right.$ clay experiments) from low and high Fe-loading samples (Fig. 3 and S8 $\dagger$ ). Fit parameters are detailed in Table S6. $\dagger$ Anoxic spectra (Fig. 3a and $b$ ) exhibited two doublets revealing the presence of ferric iron (Fe(III)) in addition to ferrous iron (Fe(II)). Accordingly, the spectra were fitted with one paramagnetic doublet with large quadrupole splitting ( $\Delta E_{\mathrm{Q}} \sim 2.68 \mathrm{~mm} \mathrm{~s}^{-1}$ ) assigned to $\mathrm{Fe}$ (II) and a second doublet with small quadrupole splitting $\left(\Delta E_{\mathrm{Q}}\right.$



Fig. 2 Derivative of normalized Fe K-edge XANES spectra of $\mathrm{Fe}^{2+}$ sorption samples in which Syn-1 $\left(\sim 5 \mathrm{~g} \mathrm{~L}^{-1}\right)$ was reacted with low $(0.25$ $\mathrm{mM}$ ) or high $(2.5 \mathrm{mM}) \mathrm{Fe}^{2+}$ concentrations at $\mathrm{pH} \sim 7$ or $\sim 8$. Sorption samples were equilibrated for 1 day under anoxic conditions (green lines) and subsequently oxidized for 1 day (orange lines). Superscripts $(a-d)$ indicate the corresponding pairs of anoxic and oxidized samples. Displayed $\mathrm{pH}$ values correspond to the $\mathrm{pH}$ measured at the end of the equilibration period for each sample. Selected reference spectra of solid phases containing Fe(II) and/or Fe(III) are shown for comparison (abbreviations: $\mathrm{Nk}=$ nikischerite, $\mathrm{Cl}-\mathrm{GR}=$ chloride green rust, $\mathrm{Fh}=$ ferrihydrite). 

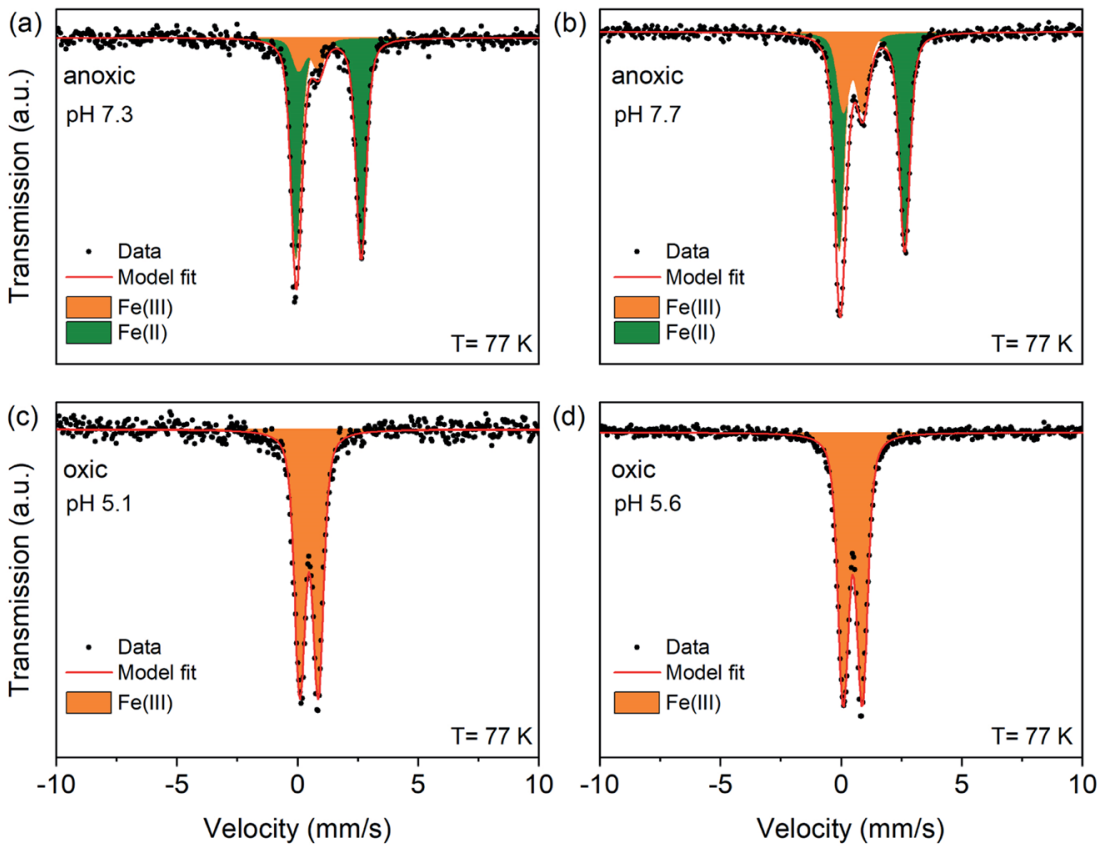

Fig. $377 \mathrm{~K}$ Mössbauer spectra and fits of high Fe-loading solid samples. Syn-1 $\left(1 \mathrm{~g} \mathrm{~L}^{-1}\right)$ was reacted with $0.5 \mathrm{mM} \mathrm{Fe}{ }^{2+}\left(\mathrm{enriched} \mathrm{in}{ }^{57} \mathrm{Fe}\right)$ at pH $\sim 7$ or $\sim 8$ under anoxic conditions during 1 day (a and b). Anoxic samples were subsequently exposed to air for 1 day (c and d). Displayed pH values correspond to the $\mathrm{pH}$ measured at the end of the equilibration period for each sample. In all graphs, symbols represent data and red lines the model fits. Corresponding fitting parameters are summarized in Table S6. $\dagger$ The Fe(॥) doublet is represented as green area and the Fe(॥I) doublet as orange area.

$\sim 0.81 \mathrm{~mm} \mathrm{~s}^{-1}$ ) consistent with Fe(III). At high Fe-loading, 14$28 \%$ of the sorbed iron was oxidized to $\mathrm{Fe}(\mathrm{III})$ under anoxic

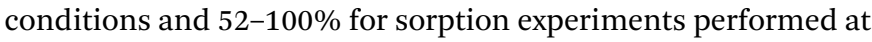
low Fe-loading (Table S6 $\dagger$ ). The ferrous doublet had similar isomer shift $(\delta)$ and quadrupole splitting $\left(\Delta E_{\mathrm{Q}}\right)$ values as were reported for chloride green rust $\left(\delta=1.27 \mathrm{~mm} \mathrm{~s}^{-1} ; \Delta E_{\mathrm{Q}}=\right.$ $\left.2.68 \mathrm{~mm} \mathrm{~s}^{-1}\right) .{ }^{45,46}$ The ferric doublet $\left(\Delta E_{\mathrm{Q}} \sim 0.81 \mathrm{~mm} \mathrm{~s}^{-1}\right.$; $\delta \sim 0.46 \mathrm{~mm} \mathrm{~s}^{-1}$ ) was consistent with poorly crystallized or amorphous compounds such as ferric hydroxide $\mathrm{Fe}(\mathrm{OH})_{3}$ or ferrihydrite. ${ }^{47}$ Overall, the data clearly show that the added $\mathrm{Fe}^{2+}$ was partially oxidized upon sorption to Syn-1 clay under anoxic conditions. The relative abundance of $\mathrm{Fe}(\mathrm{III})$ was consistently higher at the low Fe-loading (Table S6 $\dagger$ ).

The presence of $\mathrm{Fe}(\mathrm{III})$ species in anoxic sorption samples confirms that even under anoxic conditions, Fe(II) can be oxidized to $\mathrm{Fe}(\mathrm{III})$ in the presence of clay minerals with very low structural Fe contents. The amount of structural Fe present in the Syn-1 (4.65 mmol Fe per $\mathrm{kg}$ ) may have contributed to the oxidation of at maximum 0.93 and $9.3 \%$ of the added $\mathrm{Fe}^{2+}$ for high and low Fe-loading samples, respectively. Oxidation of $\mathrm{Fe}^{2+}$ by accidental exposure to $\mathrm{O}_{2}$ can be excluded as no $\mathrm{Fe}^{2+}$ oxidation was observed in $\mathrm{Fe}^{2+}$ control solutions without clay. An additional anoxic control experiment on $\mathrm{Fe}^{2+}$ sorption to Syn-1 was carried out in a glass bottle to ensure that no residual $\mathrm{O}_{2}$ sorbed to the walls of Nalgene ${ }^{\circledR}$ plastic bottles induced $\mathrm{Fe}^{2+}$ oxidation. The same results were obtained in experiments with glass and Nalgene ${ }^{\circledR}$ bottles, excluding residual sorbed $\mathrm{O}_{2}$ as a possible electron acceptor. Therefore, other reactive sites on the clay mineral surface must have induced electron transfer from $\mathrm{Fe}^{2+}$ to an electron acceptor. As only traces of $\mathrm{Ti}$ were present in the clay mineral $(1.3 \mathrm{mmol} \mathrm{Ti}$ per $\mathrm{kg})$ it can be excluded as main electron acceptor.

Géhin et al. ${ }^{14}$ suggested hydrogen to be a potential electron acceptor with the production of $\mathrm{H}_{2}$ that might be sorbed by the clay mineral and ensure the reversibility of the $\mathrm{Fe}(\mathrm{II})$ oxidation. In the study by Géhin et al. ${ }^{14}$ the $\mathrm{Fe}^{2+}$ concentration added to a Fe-free clay ( $\sim 0.06 \mathrm{mmol}$ Fe per $\mathrm{g}$ clay) was similar to the low Fe-loading sorption samples of this study. The partial pressure of $\mathrm{H}_{2}$ in both experiments was very low as they were performed in a $100 \% \quad \mathrm{~N}_{2}$ atmosphere. ${ }^{14}$ Thermodynamic calculations demonstrate that at very low $\mathrm{H}_{2}$ partial pressures, $\mathrm{H}^{+}$is a potential oxidant for $\mathrm{Fe}^{2+}$ at neutral to alkaline $\mathrm{pH}$ to form amorphous $\mathrm{Fe}(\mathrm{III})$-hydroxides (Fig. S2a $\dagger$ ). In the presence of more crystalline Fe(III) solids having lower iron solubilities such as e.g., lepidocrocite and goethite, $\mathrm{H}^{+}$would represent an even more favorable oxidant for $\mathrm{Fe}^{2+}$ and might enable $\mathrm{Fe}^{2+}$ oxidation already at slightly acidic $\mathrm{pH}$ values (Fig. $\mathrm{S} 2 \mathrm{~b} \dagger$ ). The reduction of $\mathrm{H}^{+}$would lead to the production of $\mathrm{H}_{2}$ and an increase of the partial pressure of $\mathrm{H}_{2}$. Concurrently, the $\mathrm{Fe}^{2+}$ activity is expected to decrease due to the formation of $\mathrm{Fe}(\mathrm{III})$ solid phases and progressing $\mathrm{Fe}^{2+}$ adsorption to mineral surfaces. Consequently, the ability of $\mathrm{H}^{+}$to act as an oxidant for $\mathrm{Fe}^{2+}$ decreased during sample equilibration (see arrows in Fig. S2a $\dagger$ ). This explains why the oxidation of $\mathrm{Fe}^{2+}$ was limited in our experiments. Accordingly, an increased percentage of $\mathrm{Fe}^{2+}$ oxidation with lower Fe-loading is expected, which is consistent with previous findings by Soltermann et al. and Géhin et al. ${ }^{14,30}$ confirming that the oxidation of $\mathrm{Fe}^{2+}$ is likely limited by the partial pressure of $\mathrm{H}_{2}$ and the $\mathrm{Fe}^{2+}$ activity in solution. In a control experiment without clay minerals present, $\mathrm{Fe}^{2+}$ oxidation was not observed. 
Based on this finding, we propose that clay minerals served as a catalyst for $\mathrm{Fe}^{2+}$ oxidation by $\mathrm{H}^{+}$by facilitating the electron transfer via ligation of $\mathrm{Fe}^{2+}$ to protonated surface oxygen atoms. This catalytic effect of surfaces in electron transfer reactions may be important in various environmental settings. For instance, it has been shown that the reduction of organic pollutants by $\mathrm{Fe}^{2+}$ is enhanced when sorbed to mineral surfaces. ${ }^{48-50}$

To further investigate the possible solid-phase Fe species formed during the 1 and 30 days equilibration periods, linear combination fits (LCF) of Fe K-edge EXAFS spectra were performed (Fig. 4, Tables S11 and S12 $\dagger$ ). LCF analysis showed that EXAFS spectra of high Fe-loading anoxic samples were adequately fitted by including $\mathrm{Fe}(\mathrm{II})$-hydroxide $\left(\beta\right.$ - $\left.\mathrm{Fe}(\mathrm{OH})_{2}\right)(6-$ $13 \%)$, chloride green rust $\left(\left[\mathrm{Fe}_{3}{ }^{2+} \mathrm{Fe}^{3+}(\mathrm{OH})_{8}\right] \cdot\left[\mathrm{Cl} \cdot n \mathrm{H}_{2} \mathrm{O}\right]\right)^{45}(51-$ $68 \%)$, and nikischerite $\left(\mathrm{NaFe}^{2+}{ }_{6} \mathrm{Al}_{3}\left(\mathrm{SO}_{4}\right)_{2}(\mathrm{OH})_{18}\left(\mathrm{H}_{2} \mathrm{O}\right)_{12}\right)^{51}$ (19$40 \%$ ). Nikischerite is a natural $\mathrm{Fe}(\mathrm{II})_{2} \mathrm{Al}(\mathrm{III})$-layered double hydroxide $(\mathrm{LDH})$ mineral with sulfate interlayer anions and is used here as a structural reference representing $\mathrm{Fe}(\mathrm{II}) \mathrm{Al}(\mathrm{III})-\mathrm{LDH}$ phases in general. ${ }^{51}$ Fitting of the low Fe-loading anoxic samples (Fig. 4b) required the reference compound ferrihydrite, which is in line with the presence of $\mathrm{Fe}(\mathrm{III})$ as observed by both Mössbauer and XANES spectroscopy.

An improved fit ( $>10 \%$ decrease in $R$-factor, see Table S12 $\dagger$ ) was obtained for the low Fe-loading anoxic sorption sample equilibrated at $\mathrm{pH} \sim 8$ when $\mathrm{Fe}(\mathrm{II})$-containing minerals, namely nikischerite and chloride green rust, were included. This is again consistent with the presence of Fe(II) species, as observed by Mössbauer spectroscopy. A comparison of the Fe oxidation states determined by Mössbauer spectroscopy for the $1 \mathrm{~g} \mathrm{~L}^{-1}$ batch experiments and by LCF of EXAFS spectra for $5 \mathrm{~g} \mathrm{~L}^{-1}$ batch samples is provided in Table 1 . Both sets of batch experiments are in reasonable agreement and thus confirm that $\mathrm{Fe}^{2+}$ in anoxic Fe sorption samples can partially be oxidized in the presence of Syn-1 clay.

For the majority of the samples, the LCF significantly improved when an $\mathrm{Fe}(\mathrm{III})$-containing clay mineral reference (SWy-2, containing $3 \mathrm{wt} \% \mathrm{Fe}$ ) was included as additional reference in the fits. Released Si from Syn-1 after 1 day equilibration between $\mathrm{pH} 6$ and 10 amounted on average to $\sim 0.016 \mathrm{mmol}$ Si per $\mathrm{g}$ clay compared to up to 8 times lower $\mathrm{Si}$ concentrations for anoxic sorption samples with $\mathrm{Fe}$ (see Fig. S6a and $\mathrm{S} 7 \dagger$ ). This provides additional evidence that the released $\mathrm{Si}$ from Syn-1 was removed from solution upon addition of Fe, either by adsorption or incorporation into newly formed $\mathrm{Fe}$ phases. It has been suggested by Soltermann et al. ${ }^{30}$ that $\mathrm{Fe}^{2+}$ can be taken up by the clay minerals, leading to the formation of Fe-bearing clay minerals.

In presence of elevated divalent metal $\left(\mathrm{Me}^{2+}\right)$ concentrations (first-row transition series), it has been shown that Me(II)Al-LDH
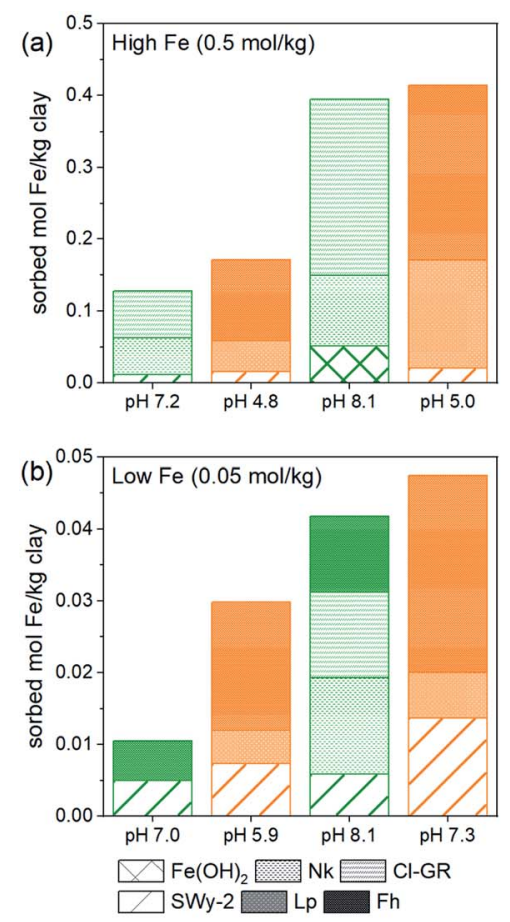

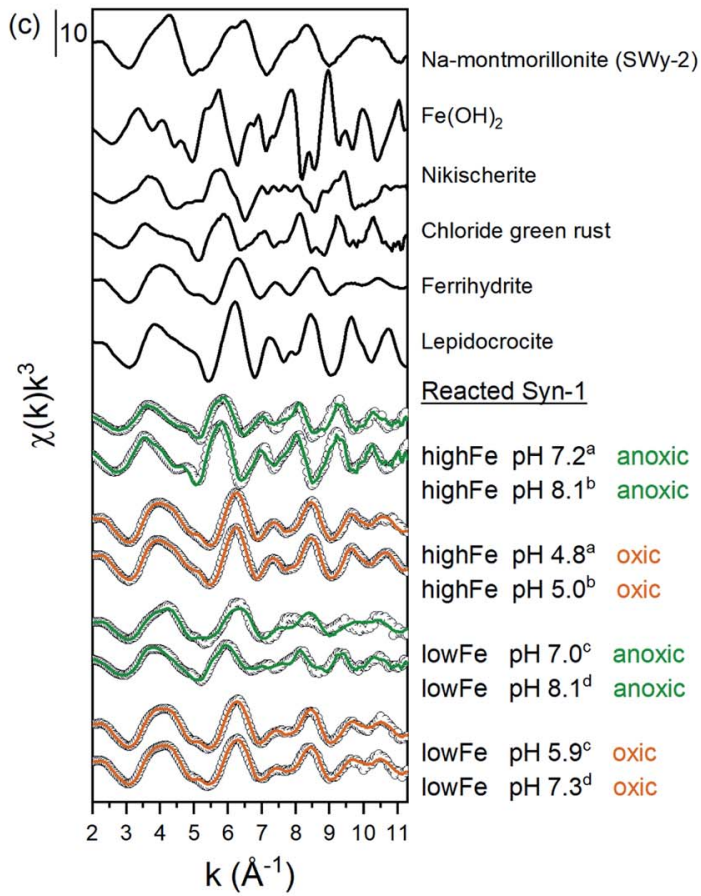

Fig. 4 LCF fitting results of Fe K-edge EXAFS spectra of $\mathrm{Fe}^{2+}$ sorption samples equilibrated for 1 day under anoxic conditions (green lines) and subsequently oxidized for 1 day (orange lines) and relevant references: ( $a$ and b) absolute fractions of Fe references obtained by linear combination fitting of $k^{3}$-weighted Fe K-edge EXAFS spectra for Fe ${ }^{2+}$ sorbed on Syn-1. High Fe load (a and c) and low (b and c) (0.25 mM) sorption samples. The fits were performed over a $k$-range of $2-11.3 \AA^{-1}\left(k_{\mathrm{w}}=3\right)$ with no fit constraints. The initial fit fractions $(70.9-146.2 \%)$ were normalized to the sum equal to $100 \%$ and are reported in Tables S11 and S12† (abbreviations: $\mathrm{Nk}=$ nikischerite, $\mathrm{Cl}-\mathrm{GR}=\mathrm{chloride}$ green rust, $\mathrm{Lp}=$ lepidocrocite, $\mathrm{Fh}=$ ferrihydrite). (c) $k^{3}$-weighted $\chi$ spectra of references (line): $\mathrm{SWy}-2, \mathrm{Fe}(\mathrm{OH})_{2}$, nikischerite, chloride green rust, ferrihydrite and lepidocrocite are shown together with the $k^{3}$-weighted $\chi$ spectra (open circles) of 1 day equilibrated samples with corresponding fit (green and orange colors correspond to anoxic and oxidized samples, respectively). Displayed $\mathrm{pH}$ values correspond to the $\mathrm{pH}$ measured at the end of the equilibration period for each sample. Superscripts $(a-d)$ indicate the corresponding pairs of anoxic and oxidized samples. 
Table 1 Percentage of Fe(॥) and Fe(III) based on ${ }^{57} \mathrm{Fe}-\mathrm{Mössbauer}$ and Fe K-edge EXAFS spectra (LCF of $k^{3}$-weighted spectra) ${ }^{b}$

\begin{tabular}{|c|c|c|c|c|c|}
\hline \multirow[b]{2}{*}{ High Fe load } & \multirow[b]{2}{*}{ Anoxic target pH } & \multicolumn{2}{|c|}{ EXAFS } & \multicolumn{2}{|c|}{ Mössbauer } \\
\hline & & $\mathrm{Fe}(\mathrm{II})^{a}$ & $\mathrm{Fe}(\mathrm{III})^{a}$ & $\mathrm{Fe}(\mathrm{II})$ & $\mathrm{Fe}(\mathrm{III})$ \\
\hline Anoxic & 7 & 78 & 22 & $86(1.3)$ & $14(1.3)$ \\
\hline Anoxic & 8 & 84 & 16 & $72(0.6)$ & $28(0.6)$ \\
\hline Oxic & 7 & 0 & 100 & 0 & 100 \\
\hline \multirow[t]{2}{*}{ Oxic } & 8 & 0 & 100 & 0 & 100 \\
\hline & & \multicolumn{2}{|c|}{ EXAFS } & \multicolumn{2}{|c|}{ Mössbauer } \\
\hline Low Fe load & Anoxic target pH & $\mathrm{Fe}(\mathrm{II})^{a}$ & $\mathrm{Fe}(\mathrm{III})^{a}$ & $\mathrm{Fe}(\mathrm{II})$ & $\mathrm{Fe}($ III) \\
\hline Anoxic & 7 & 0 & 100 & $\begin{array}{c}0 \\
48(04)\end{array}$ & 100 \\
\hline Anoxic & 8 & 54 & 46 & $48(0.4)$ & $52(0.4)$ \\
\hline
\end{tabular}

${ }^{a}$ Assumption of a $3 / 1 \mathrm{Fe}(\mathrm{II}) / \mathrm{Fe}(\mathrm{III})$ ratio as in stoichiometrically pure ClGR. ${ }^{b}$ Note: parameter uncertainties are given in parentheses.

can form under alkaline conditions in the presence of Al-

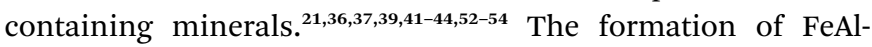
$\mathrm{LDH}$ phases is favored over $\mathrm{Fe}(\mathrm{OH})_{2}$ in environments where $\mathrm{Al}^{3+}$ is present because FeAl-LDH phases are less soluble than $\mathrm{Fe}(\mathrm{OH})_{2}$ by two orders of magnitude. ${ }^{54}$ Yet, partial oxidation of $\mathrm{Fe}(\mathrm{OH})_{2}$ would lead to the formation of green rust, for which no information is available concerning its stability compared to FeAl-LDH.

The contributions of $\mathrm{Fe}(\mathrm{OH})_{2}, \mathrm{Cl}-\mathrm{GR}$, and nikischerite to the LCF of EXAFS spectra of high Fe-loading anoxic samples suggest that under our experimental conditions, $\mathrm{Fe}^{2+}$ was mainly sorbed through the formation of $\mathrm{Fe}^{2+}$-containing layered mineral phases. Furthermore, the inclusion of a reference spectrum for aqueous $\mathrm{Fe}^{2+}$ in the LCF did not improve the fits significantly, confirming that outer-sphere adsorption of $\mathrm{Fe}^{2+}$ to the clay surface was not an important sorption mechanism at neutral to weakly alkaline $\mathrm{pH}$.

The goodness of fit in the LCF analysis of anoxic sorption samples was not fully satisfactory ( $R$-factors $>5 \%$, Tables S11 and $\mathrm{S} 12 \dagger)$. Therefore, we further analyzed the data by shell-byshell fitting of Fourier transformed (FT), $k^{3}$-weighted EXAFS spectra (Fig. S11†), which is independent of reference spectra and may provide additional information about the average bonding environment of $\mathrm{Fe}$ in the samples. ${ }^{55}$ For all anoxic sorption samples, a first shell was observed at $\sim 1.5 \AA$ (uncorrected for phase shift), representing the first oxygen shell surrounding the central Fe atoms. Further shells with $R+\Delta R$ between 2 and $3.5 \AA$ were observed, which could be attributed to $\mathrm{Fe}-\mathrm{Fe}, \mathrm{Fe}-\mathrm{Al}$, or $\mathrm{Fe}-\mathrm{Si}$ backscattering pairs.

For high Fe-loading anoxic samples (Tables 2 and S13†), the first shell was fitted with 4.1-5.4 $\mathrm{O}$ atoms at a distance of 2.10$2.12 \AA$, which is characteristic of an octahedral arrangement of $\mathrm{O}$ around $\mathrm{Fe}(\mathrm{II})$. The second shell at $\sim 2.8 \AA$ (uncorrected for phase shift) can be fitted with $\mathrm{Fe}$ and $\mathrm{Al}$ or $\mathrm{Si}$ backscatterers. ${ }^{51,56,57}$ Due to the similar or even same crystallographic position of $\mathrm{Fe}^{2+}$, and $\mathrm{Al}^{3+}$ in $\mathrm{LDH}$, it is difficult to unequivocally differentiate these two atoms. Additionally, constructive interferences from $\mathrm{Si}^{4+}$ atoms in greenalite, ${ }^{57}$ which are found at slightly larger crystallographic positions than $\mathrm{Fe}^{2+}$ and $\mathrm{Al}^{3+}$, could occur. Wavelet transformation (WT) of EXAFS spectra can complement the FT by resolving the $k$ dependence of the absorption signal, allowing better distinction between heavier and lighter backscattering atoms. The WT of the second coordination shell of the high Fe-loading anoxic samples and Fe references are shown in Fig. S13 and S14. $\dagger$ Unfortunately, WT did not allow for the distinction between Al and $\mathrm{Fe}$ path contribution to the second shell as both nikischerite and chloride green rust possessed a peak at $k \sim 6 \AA^{-1}$. Therefore, three models with different single scattering paths for fitting the second shell in high Fe-loading anoxic samples were compared (Table S16 and Fig. S12†). Model 1 with only a second shell Fe-Fe path, Model 2 with Fe-Fe and Fe-Al paths, and Model 3 with $\mathrm{Fe}-\mathrm{Fe}$ and $\mathrm{Fe}-\mathrm{Si}$ paths, respectively. Model 1 returned a Fe-Fe distance of 3.20-3.21 $\AA$, in agreement with crystallographic data of chloride green rust. ${ }^{56}$ Including an additional $\mathrm{Fe}-\mathrm{Al}$ path (Model 2) resulted in a $\mathrm{Fe}-\mathrm{Al}$ distance of $3.30 \AA$, which is significantly different from the $\mathrm{Fe}-\mathrm{Al}$ distance in FeAl-LDH phases like nikischerite (3.12 Å). ${ }^{51}$ Similarly, including an additional Fe-Si path (Model 3) resulted in a fitted Fe-Si distance of $3.19 \AA$, which differs from the Fe-Si distance in greenalite $(3.30 \AA) .{ }^{57}$ Additionally, the inclusion of a $\mathrm{Fe}-\mathrm{Al}$ or $\mathrm{Fe}-$ Si backscattering path to Model 1 did not decreased the reduced $\chi^{2}$-values by at least a factor two. ${ }^{55}$ Based on these results, Model 2 and 3 might not be suitable for the fitting of high Fe-loading anoxic samples. The aforementioned findings suggest that in high Fe-loading anoxic sorption samples mainly a LDH phase with Fe in the octahedral sheet formed. However, WT of EXAFS spectra of high Fe-load samples displayed as an intermediate between FeAl-LDH and Cl-GR, which might suggest that $\mathrm{Al}$ released from the clay minerals (see Fig. $\mathrm{S} 6 \mathrm{~b} \dagger$ ) was incorporated into the octahedral sheets of the newly formed Fe-phase. This is in agreement with the LCF fits of high Fe-loading anoxic sorption samples, which required both the nikischerite and Cl-GR reference. Therefore, it is likely that a mixed $\mathrm{Fe}(\mathrm{II})-\mathrm{Al}(\mathrm{III}) / \mathrm{Fe}(\mathrm{III})$ $\mathrm{LDH}$ phase formed under these conditions, as suggested by Starcher et $a .^{\mathbf{4 4}}$

In order to obtain information about the orientation of the newly formed secondary phases polarized EXAFS (P-EXAFS) spectra were recorded for the high Fe-loading sorption samples. In P-EXAFS neighbouring atoms along the electric field (or along polarization direction of the X-ray beam) are preferentially probed and atoms located in a plane perpendicular to this electric field direction are attenuated. Applying this method to clay mineral self-supporting films has the advantage of minimizing the contribution of cations from the tetrahedral sheets by orienting the layer ab plane to the electric field. Conversely, the contributions of cations from the octahedral sheet is extinguished in the perpendicular orientation of the electric field. The P-EXAFS spectra of the oriented high Feloading sorption sample recorded at $\alpha=10^{\circ}, 35^{\circ}, 55^{\circ}$ and $80^{\circ}$ are presented in Fig. S15. $\dagger$ The presence of isosbestic points in the spectra provides evidence that the differences in the measured spectra were only due to orientation effects. ${ }^{58-61}$ The pronounced dependence upon orientation in the regions 
Table 2 Shell-fit parameters determined from Fe K-edge EXAFS data of Fe(I) sorption to Syn-1 under anoxic conditions for 1 day. ${ }^{a}$ Parameter uncertainties are given in parentheses

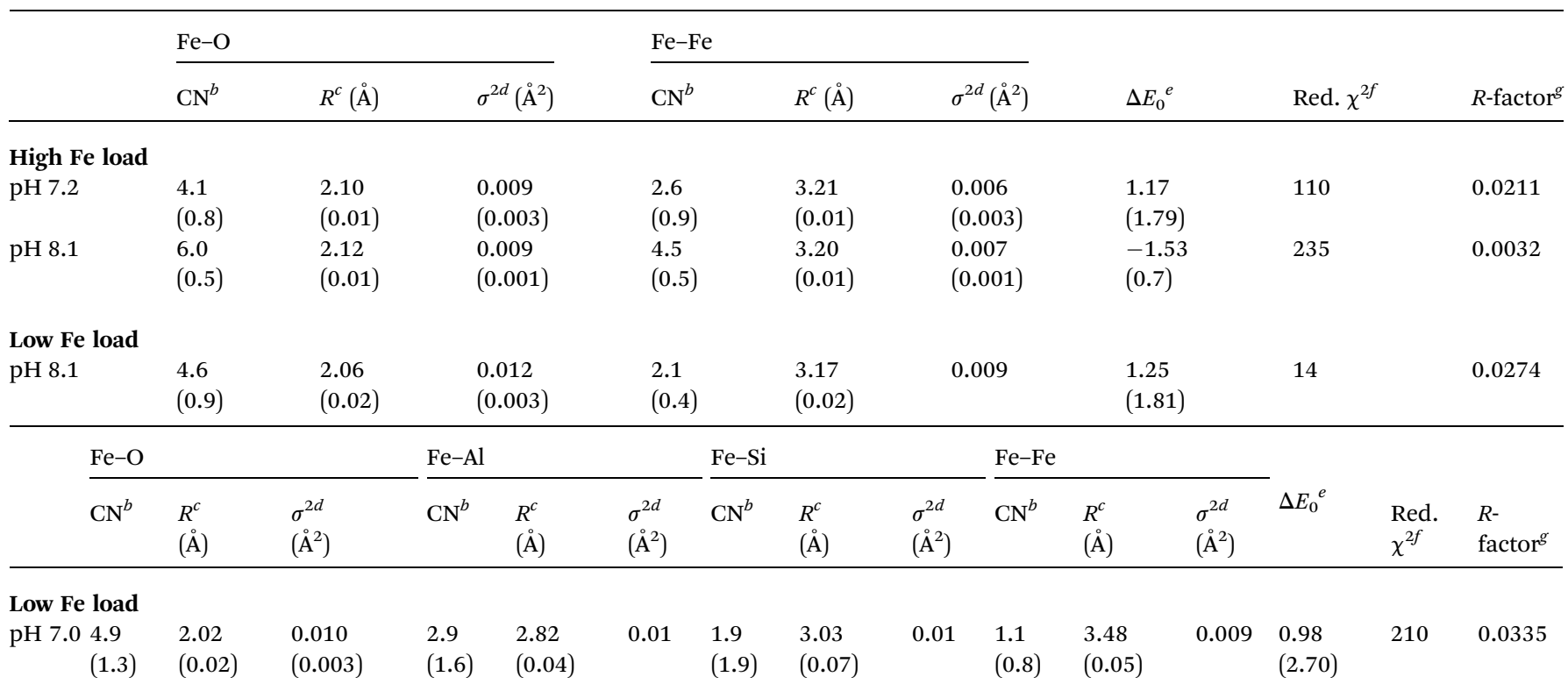

${ }^{a}$ The amplitude reduction factor $S_{0}{ }^{2}$, was set to 0.9 based on first shell optimization for all sorption samples $(R$-range $1.1-2.5 \AA) .{ }^{b}$ Path degeneracy (coordination number). ${ }^{c}$ Mean half path length. ${ }^{d}$ Debye-Waller parameter. Debye-Waller parameter was fixed to $0.01 \AA^{2}$ for Fe-Al and Fe-Si based on the $\sigma^{2}$ obtained for $\mathrm{Fe}-\mathrm{Si}$ and $\mathrm{Fe}-\mathrm{Al}$ path by Soltermann et al..$^{30} \sigma^{2}(\mathrm{Fe})$ was fixed to $0.009 \AA^{2}$ for Fe-Fe of low Fe-load sorption sample like was fitted for edge-sharing $\mathrm{Fe}-\mathrm{Fe}$ for low Fe-load samples. ${ }^{e}$ Energy-shift parameter. ${ }^{f}$ Fit accuracy; reduced $\chi^{2}=\left(N_{\text {idp }} / N_{\text {pts }}\right) \sum_{i}\left(\left(\text { data }_{i}-\text { fit }_{i}\right) / \varepsilon_{i}\right)^{2}\left(N_{\text {idp }}-N_{\text {var }}\right)^{-1} \cdot N_{\text {idp }}, N_{\text {pts }}$ and $N_{\text {var }}$ are, respectively, the number of independent points in the model fit (11.2-13.7), the total number of data points (151-171), and the number of fit variables $(6-10) . \varepsilon_{\mathrm{i}}$ is the uncertainty of the $\mathrm{i}^{\text {th }}$ data point. ${ }^{g} R$ factor; Normalized sum of squared residuals $\left(\sum_{i}\left(\text { data }_{i}-\mathrm{fit}_{i}\right)^{2} / \sum_{i} \mathrm{data}^{2}\right)$. Note: The FT of $k^{3}$-weighted EXAFS spectrum of the anoxic low Feloading samples at pH 8.1 was calculated over a $k$-range of $2-9.5 \AA^{-1}$. The shell-fit analysis of $k^{3}$-weighted Fe EXAFS spectrum of the anoxic low Fe-loading sample at $\mathrm{pH} 7.0$ was performed in $R$-space $R+\Delta R$-range of $1.1-4 \AA$.

between the isosbestic points confirms the successful preparation of a clay film with preferred orientation. ${ }^{59-62}$ The angle dependence of the spectra also confirms the anisotropic formation of the secondary phase aligned with the clay mineral sheets for high Fe-loading anoxic sorption samples.

For the low Fe-loading anoxic samples, the first shell was fitted with 4.6-5.3 O atoms at a radial distance of 2.01-2.05 which is an intermediate distance of an octahedral arrangement of $\mathrm{O}$ atoms around $\mathrm{Fe}(\mathrm{II})$ and $\mathrm{Fe}(\mathrm{III}) .{ }^{56,63}$ The fitting of a $\mathrm{CN}<6$ may suggest the presence of some tetrahedral $\mathrm{Fe}$ as found in ferrihydrite. This result is in agreement with the presence of $\mathrm{Fh}$ in the LCF of EXAFS spectra of this sample (Table S12 $\dagger$ ).

The FT of the EXAFS spectra of the low Fe-loading anoxic samples equilibrated at $\mathrm{pH} \sim 8$, showed a second peak at $\sim 2.75$ $\AA$ (uncorrected for phase shift). This second shell was fitted with Fe located at a radial distance of 3.15-3.17 $\AA$ and a coordination number of 1.8-2.1. The fitted distance for the second shell corresponds with an intermediate distance of edge-sharing Fe atoms around $\mathrm{Fe}(\mathrm{II})$ and $\mathrm{Fe}(\mathrm{III})$ as in fougerite $^{56}$ and lepidocrocite, ${ }^{64}$ respectively. This is consistent with the results obtained by LCF and Mössbauer spectroscopy.

The low Fe-loading anoxic sample equilibrated at $\mathrm{pH} \sim 7$ (Table 2) showed two overlapping small peak after the first shell, one at $\sim 2.3 \AA$ and $\sim 3.1 \AA$ (uncorrected for phase shift). Fitting of these two shells required a $\mathrm{Fe}-\mathrm{Al}, \mathrm{Fe}-\mathrm{Si}$ and $\mathrm{Fe}-\mathrm{Fe}$ backscattering path with distances of 2.84, 3.08 and $3.48 \AA$, respectively. Fitted distances for $\mathrm{Fe}-\mathrm{Al}$ and $\mathrm{Fe}-\mathrm{Si}$ paths are in good agreement with bond distances in phyllosilicates. ${ }^{65}$ The distance fitted for the Fe-Fe path at $3.48 \AA$ is characteristic for double corner-sharing $\mathrm{Fe}$ as in ferrihydrite. ${ }^{\mathbf{6 3 , 6 6}}$

The WT of EXAFS spectra of low Fe-loading anoxic sample equilibrated at $\mathrm{pH} \sim 7$ (see Fig. S14c $\dagger$ ) contained three maxima, one at $k=3,7$, and $10 \AA^{-1}$ suggesting three different backscattering atoms contributing to the second shell. This result confirms that including the $\mathrm{Fe}-\mathrm{Fe}, \mathrm{Fe}-\mathrm{Al}$ and $\mathrm{Fe}-\mathrm{Si}$ backscattering paths in the model to fit low Fe-loading anoxic samples equilibrated at $\mathrm{pH} \sim 7$ is reasonable. Additionally, $F$-tests confirmed that the inclusion of $\mathrm{Fe}-\mathrm{Al}$ and $\mathrm{Fe}-\mathrm{Si}$ backscattering paths into the fit model significantly improved the goodness of the fit (S.I. Section $11 \dagger$ ).

Previous studies have also investigated the sorption of $\mathrm{Fe}^{2+}$ to different clay minerals at various Fe-loadings. ${ }^{\mathbf{1 4 , 3 0}}$ Collectively, the literature results suggested that depending on the Feloading, various Fe(II)- and Fe(III)-containing solids formed. At high Fe-loadings (0.53-2 mol Fe per $\mathrm{kg}$ ) the formed secondary phases were predominantly Fe(II)-containing phases. ${ }^{19,21}$ At low Fe-loadings (0.002-0.08 mol Fe per kg) mainly Fe(III)-containing phases were observed. ${ }^{30,67}$ Our current study are in agreement 
with these results. The formation of an $\mathrm{LDH}$ phase with $\mathrm{Fe}$ in the octahedral sheet was observed for high Fe-loading anoxic sorption samples as shown by Jones et al. ${ }^{19}$ Contrary, in the study by Zhu et al. ${ }^{21}$ no $\mathrm{Fe}^{2+}$ oxidation was observed during sorption of $\mathrm{Fe}^{2+}$ onto Syn-1 and the formation of FeAl-LDH was suggested as the main solid phase forming. However, sorption experiments in the study by $\mathrm{Zhu}$ et al. were performed in an atmosphere with $5 \% \mathrm{H}_{2}$ and $95 \% \mathrm{~N}_{2}$. Such elevated $\mathrm{H}_{2}$ concentration are expected to disable $\mathrm{H}^{+}$to oxidize $\mathrm{Fe}^{2+}$ (cf. Fig. $\mathrm{S} 2 \dagger)$ and to suppress the formation of green rust as the main secondary phase. In our low Fe-loading samples, over half of $\mathrm{Fe}(\mathrm{II})$ was oxidized to $\mathrm{Fe}(\mathrm{III})$, from which a large fraction was incorporated into newly formed clay minerals. This result shows that clay minerals can play an important role in the mobility of $\mathrm{Fe}^{2+}$ under anoxic conditions.

\section{Effects of aeration of anoxic sorption samples on Fe speciation}

To understand the effects of $\mathrm{O}_{2}$-exposure on the speciation of $\mathrm{Fe}$ in clay suspensions (Syn-1) that were anoxically equilibrated for 1 or 30 days with $\mathrm{Fe}^{2+}$, the anoxic suspensions were exposed to ambient air for 24 hours. Aeration resulted in a further increase in percent Fe sorption (see Fig. $4 \mathrm{a}, \mathrm{b}$ and Table S $2 \dagger$ ), despite a drop in suspension $\mathrm{pH}$ (between 0.8 and $3.1 \mathrm{pH}$ values) as a result of hydrolysis of $\mathrm{Fe}^{3+}$ (Table S3†). Due to the high $\mathrm{O}_{2}$ sensitivity of $\mathrm{Fe}^{2+}$ at near-neutral $\mathrm{pH}$, rapid oxidation of adsorbed and dissolved $\mathrm{Fe}^{2+}$, hydrolysis of $\mathrm{Fe}^{3+}$, and precipitation of $\mathrm{Fe}(\mathrm{III})$-(oxyhydr)oxides may occur. This results in the release of protons, explaining the observed decrease of suspension $\mathrm{pH}$.

After the equilibration of $\mathrm{Fe}^{2+}$ with Syn-1 under anoxic conditions, substantial amounts of aqueous $\mathrm{Fe}^{2+}$ still remained in solution (70-78\% of added $\mathrm{Fe}$ at $\mathrm{pH} \sim 7$ and $7-16 \%$ at $\mathrm{pH} \sim 8$, see Table $\mathrm{S} 2 \dagger$ ). Additionally, some adsorbed $\mathrm{Fe}^{2+}$ may have been desorbed from clay surfaces as $\mathrm{pH}$ started to decrease. All dissolved and adsorbed $\mathrm{Fe}^{2+}$ is expected to rapidly oxidize upon exposure to $\mathrm{O}_{2}$ and form iron minerals such as lepidocrocite and/or ferrihydrite, depending on solution composition (e.g., $\mathrm{Ca}, \mathrm{Si}$ ). ${ }^{68}$ However, the remaining 22 to $30 \%$ (at $\mathrm{pH} \sim 7$ ) or 83 to $93 \%$ ( $\mathrm{pH} \sim 8$ ) of the added Fe was sorbed to the clay, mostly by the formation of $\mathrm{Fe}$ (II) solid phases such as chloride green rust, FeAl-LDH, and/or Fe(III)-phyllosilicates, as was shown in the section above. The oxidation kinetics and resulting Fe species formed during aeration of such sorbed ferric Fe on clay minerals is far less understood.

Mössbauer spectroscopy showed that the $24 \mathrm{~h}$ aeration of anoxic $\mathrm{Fe}^{2+}$ sorption samples led to a complete oxidation of all added Fe, resulting in only a ferric doublet in the spectra of oxic samples (Fig. 3c and d). This finding shows that even 30 days equilibration under anoxic conditions, resulting in mainly the incorporation of $\mathrm{Fe}(\mathrm{II})$ into solid phases, did not prevent rapid oxidation to Fe(III). Additional Mössbauer spectra of two high Fe-loading oxic samples were measured at 45, 35, 25 and $15 \mathrm{~K}$ (Fig. S10 $\dagger$ ). The fitting results of the temperature-dependent Mössbauer spectra are given in Tables S7 and S8. $\dagger$ In general, the spectra displayed the characteristic effect of magnetic ordering with decreasing temperature. Ordered sextets had hyperfine parameters $\delta$ (between 0.49 and $0.50 \mathrm{~mm} \mathrm{~s}^{-1}$ ), $\Delta E_{\mathrm{Q}}$ (between -0.05 and $-0.01 \mathrm{~mm} \mathrm{~s}^{-1}$ ) and hyperfine field $\left(B_{\mathrm{hf}}\right)$ (between 43.9 and $44.3 \mathrm{~T}$ ) for the oxic samples at $15 \mathrm{~K}$, which are in line with values reported for short range ordered Fe(III)-oxyhydroxides such as lepidocrocite and ferrihydrite. ${ }^{69}$ Additionally, temperature dependent Mössbauer spectra allow the determination of the blocking temperature, which is affected by crystallite size or interparticle interactions. ${ }^{\mathbf{7 0 , 7 1}}$ We calculated the blocking temperature as the temperature at which the summed areas of the paramagnetic doublets and magnetic sextets (which includes poorly ordered and fully magnetically ordered sextets) of Mössbauer spectra are equal. Fig. S9† shows the relative abundance of doublets and sextets for the two oxic samples at pH 5.1 ( $\mathrm{pH} 7.3$ under anoxic conditions) and pH 5.6 ( $\mathrm{pH} 8.4$ under anoxic conditions). Both samples displayed a blocking temperature below the literature values for ferrihydrite and lepidocrocite (between 50 and $77 \mathrm{~K}$ ) ${ }^{69,72}$ A blocking temperature of $\sim 32 \mathrm{~K}$ was calculated for the oxic sample preequilibrated at $\mathrm{pH} 7.3$, compared to $\sim 42 \mathrm{~K}$ for the aerated suspension pre-equilibrated at $\mathrm{pH}$ 8.4. This indicates that oxidation of the anoxic sorption samples led to the formation of short range ordered $\mathrm{Fe}(\mathrm{III})$-(oxyhydr)oxides, for which either precipitates had smaller crystallite size or show a lesser degree of interparticle interaction, potentially as a result of surface sorption effects, when formed at $\mathrm{pH} 7.3$ than $\mathrm{pH}$ 8.4.

For all oxic sorption samples, the position of the Fe K-edge was at $7127 \mathrm{eV}$ (Fig. 2), which corresponds to the oxidation state Fe(III) and is in line with Mössbauer data (Fig. 2). Linear combination fitting (LCF) results for Fe K-edge EXAFS spectra are presented in Fig. 4 (also Tables S11 and S12†). Oxidized sorption samples were well described $(R$-factor $<2 \%)$ with 3 reference compounds: ferrihydrite (45-60\%), Fe(III)-containing phyllosilicates (24-36\%), and lepidocrocite (13-19\%). Essentially, all oxic sorption samples transformed into the same secondary phases regardless of their equilibration conditions ( $\mathrm{pH}, \mathrm{Fe}$ concentration) and time ( 1 or 30 days) under anoxic conditions (Tables S11 and $12 \dagger$ ). Parts of the Fe(III)-containing phyllosilicates that have already formed under anoxic conditions were not affected by oxidation and remained as secondary phase after aeration. It was observed that the fraction of lepidocrocite formed was significantly lower for low Fe-loading samples compared to high Fe-loading samples.

The oxidation of aqueous ferrous iron at pH 7 and in a chloride background is known to lead to the formation of lepidocrocite, with crystallinity decreasing with decreasing $\mathrm{pH}^{27}$ Below $\mathrm{pH} 4$, oxidation of ferrous iron is expected to precipitate as ferrihydrite. ${ }^{27}$ As the $\mathrm{pH}$ of the oxic sorption samples remained above $\mathrm{pH} 4$ and the concentration of $\mathrm{Ca}$ was elevated, the formation of lepidocrocite as the major Fe(III)-(oxyhydr)oxides is expected. However, the presence of dissolved silicate, released from the clay mineral, above $10 \mu \mathrm{mol} \mathrm{L}^{-1}$ has been shown to inhibit the formation of more crystalline iron oxides, such as lepidocrocite, ${ }^{73}$ and favor the formation of ferrihydrite. ${ }^{6,68}$ Therefore, the observation of ferrihydrite as the dominant secondary phase under oxic conditions in this study was more anticipated, as Si released from the clay mineral amounted to $\sim 80 \mu \mathrm{mol} \mathrm{Si} \mathrm{L}^{-1}$ between $\mathrm{pH} 6$ and 10 (Fig. S6a $\dagger$ ). The 
observation of lepidocrocite as a second Fe(III)-(oxyhydr)oxides in the oxic samples can be explained by two mechanisms: (i) through the oxidation of green rust, which under certain conditions can be oxidized into lepidocrocite ${ }^{28}$ or (ii) through dissolved ferrous iron catalyzing the transformation of poorly-crystalline ferrihydrite to the more stable mineral lepidocrocite. ${ }^{74,75}$

A lower amount of lepidocrocite was formed in the low Feload samples, as direct oxidation of $\mathrm{Fe}^{2+}$ in presence of elevated $\mathrm{Si}$ concentrations (high $\mathrm{Si} / \mathrm{Fe}$ ratio in solution) may mainly precipitate as ferrihydrite. ${ }^{73}$ However, only a small fraction of the sorbed $\mathrm{Fe}$ in the oxic samples was formed by direct oxidation of dissolved $\mathrm{Fe}^{2+}$ for low Fe-loading samples equilibrated at $\mathrm{pH} \sim 8$ (between 7 and $12 \%$, see Fig. S4 and $\mathrm{S} 5 \dagger$ ) compared to samples equilibrated at $\mathrm{pH} \sim 7$ (between 60 and $65 \%$, see Fig. S4 and S5†). Nevertheless both low Fe-loading samples resulted in the presence of similar solid phases. The higher fraction of lepidocrocite observed in the high Fe-loading oxic samples as compared to the low Fe-loading samples may be due to the oxidation of dissolved $\mathrm{Fe}^{2+}$ in the presence of a low Si/ Fe ratio in solutions, which favors lepidocrocite formation over ferrihydrite or through the transformation of green rust into lepidocrocite. ${ }^{66,73}$ Because only a small fraction of the sorbed Fe (up to $20 \%$, see Fig. S4 and S5 $\dagger$ ) was formed by direct oxidation of dissolved $\mathrm{Fe}^{2+}$ in high Fe-loading samples, lepidocrocite was primarily formed from the transformation of Fe-phases precipitated under anoxic conditions.

The LCF of EXAFS spectra of oxic samples significantly improved when an $\mathrm{Fe}(\mathrm{III})$-containing clay mineral reference (SWy-2, representing $\mathrm{Fe}(\mathrm{III})$ in phyllosilicate structures) was included. Furthermore, measured $\mathrm{Si}$ in solution of oxic samples was 6-40 times lower than the Si released from Syn- 1 after 1 day equilibration between $\mathrm{pH} 6$ and 10 in absence of $\mathrm{Fe}$ ( $\sim 0.016 \mathrm{mmol}$ Si per g clay) (Fig. S6a and S7 $\dagger$ ). Combined, this provides strong evidence for sorption and/or incorporation of $\mathrm{Si}$ into the Fe species formed upon aeration. Based on the LCF results, the amount of Fe sorbed by the formation of Fephyllosilicates (the fraction fitted by SWy-2) was calculated. Together with amount $\mathrm{Si}$ re-sorbed upon $\mathrm{Fe}^{2+}$ addition, this allowed to calculate the ratio of Fe to Si sorbed in the samples. The overall $\mathrm{Fe} / \mathrm{Si}$ ratio of the newly formed $\mathrm{Fe}$ species was estimated to amount to $0.56-1.83$ (Tables S4 and S5†). These values are in line with $\mathrm{Fe} / \mathrm{Si}$ ratios one would expect for $1: 1 \mathrm{Fe}-$ phyllosilicate, like $\left(\mathrm{Fe}^{2+}, \mathrm{Fe}^{3+}\right)_{3-2} \mathrm{Si}_{2} \mathrm{O}_{5} \mathrm{OH}$ and $2: 1$ Fephyllosilicate $\left(\left(\mathrm{Fe}^{2+}, \mathrm{Fe}^{3+}\right)_{3-2} \mathrm{Si}_{4} \mathrm{O}_{10}(\mathrm{OH})_{2}\right){ }^{.6}$

More detailed information about changes in local coordination environment of $\mathrm{Fe}$ upon aeration of the suspensions was obtained by shell-by-shell fitting of fourier transformed $k^{3}$ weighted Fe K-edge EXAFS spectra (Fig. S11†). All oxic sorption samples showed a first shell at $\sim 1.5 \AA$ (uncorrected for phase shift), representing the first oxygen shell surrounding the Fe atoms. A second shell was observed between 2 and $3.5 \AA$, which can be attributed to different $\mathrm{Fe}-\mathrm{Fe}$ backscattering pairs. The first shell was fitted with 4.9-6.0 $\mathrm{O}$ atoms at a radial distance of 1.99-2.00 ̊. This is consistent with an octahedral arrangement of the $\mathrm{O}$ atoms around a central $\mathrm{Fe}(\mathrm{III})$, as in lepidocrocite. ${ }^{63}$ The fitting of a $\mathrm{CN}$ smaller than 6 may suggest the presence of some tetrahedral $\mathrm{Fe}$ as found in ferrihydrite. ${ }^{77}$ This result is in agreement with the presence of Fh in the LCF of EXAFS spectra of oxic sample (Tables S11 and S12†). The second shell was composed of two peaks, one at $\sim 2.65 \AA$ and a second peak at $\sim 3.11 \AA$ (uncorrected for phase shift). These two peaks were successfully fitted with two Fe-Fe single backscattering paths. The first Fe backscattering path $\left(\mathrm{Fe}^{-} \mathrm{Fe}_{1}\right)$ had a fitted distance of 3.07-3.09 $\AA$ with coordination numbers between 1.8-3.7, consistent with edge-sharing $\mathrm{Fe}$ octahedral. ${ }^{64}$ The second $\mathrm{Fe}$ backscattering path $\left(\mathrm{Fe}^{-} \mathrm{Fe}_{2}\right)$ had a fitted distance of 3.42-3.45 $\mathrm{\AA}$ with coordination numbers between 1.2-2.1, characteristic of double corner-sharing Fe octahedral. ${ }^{63,66}$ The fitted coordination numbers of edge-sharing $\mathrm{Fe}\left(\mathrm{Fe}-\mathrm{Fe}_{1}\right)$ atoms increased with increasing Fe-loading, contrary to the fitted coordination numbers of corner-sharing $\mathrm{Fe}\left(\mathrm{Fe}-\mathrm{Fe}_{2}\right)$ atoms (Tables $\mathrm{S} 14$ and $\mathrm{S} 15 \dagger)$. These trends correspond well with the increasing fraction of lepidocrocite formed with increasing Fe-loading, as observed by LCF of EXAFS spectra of oxic sorption samples. Triangular multiple scattering (MS) paths $\mathrm{Fe}-\mathrm{O}-\mathrm{O}$ were not implemented in our fit model as including this path decreased the reduced $\chi^{2}$ values less than a factor two (see S.I. Section 15 for details $\dagger$ ). ${ }^{55}$

\section{Conclusions}

Our results show that the formation of Fe-bearing secondary phases is the main sorption mechanism for $\mathrm{Fe}^{2+}$ uptake by clay minerals low in structural Fe under anoxic conditions. Clay minerals can enhance the formation of newly formed, layered Fe minerals such as green rusts, FeAl-LDH, and Fephyllosilicates, by providing nucleation sites and serving as a source of Al and Si. Furthermore, clay surfaces may act as catalysts for $\mathrm{Fe}^{2+}$ oxidation by hydrogen, especially at circumneutral to alkaline $\mathrm{pH}$ values and low $\mathrm{H}_{2}$ partial pressures. Therefore, the precipitation of Fe-bearing phases in presence of clays may be of importance in controlling $\mathrm{Fe}^{2+}$ solubility in anoxic groundwaters and soils.

The nature of the secondary phases formed under anoxic conditions appeared to be controlled by Fe-loading, but also by other factors. Under the conditions used in our study (high $\mathrm{Ca}^{2+}$, no $\mathrm{CO}_{2}$ ), the formation of layered Fe minerals was favored. These conditions were chosen to ensure saturation of cation exchange sites with $\mathrm{Ca}^{2+}$ and exclude formation of iron carbonates, allowing us to identify the sorption mechanisms of $\mathrm{Fe}^{2+}$ to edge sites of the clay mineral. However, as submerged soils frequently contain elevated $\mathrm{CO}_{2}$ concentrations, the precipitation of carbonate green rust and also siderite $\left(\mathrm{FeCO}_{3}\right)$ would also be expected in these environments.

After exposure of anoxic sorption samples to ambient air, sorbed $\mathrm{Fe}(\mathrm{II})$ was completely oxidized to Fe(III). Aeration led to a rapid transformation of sorbed Fe into ferrihydrite, lepidocrocite, and Fe(III)-bearing clay minerals, independent of the Fe-loading and the duration of the pre-equilibration under anoxic conditions. This demonstrates that clay minerals are unable to stabilize sorbed Fe(II) against oxidation. However, the presence of clay minerals favors the formation of $\mathrm{Fe}(\mathrm{III})$-containing clays both under anoxic and oxic conditions. This process is expected to impact not only the solubility of iron in soils and sediments but also many redox transformations of 
organic and inorganic contaminants which can react with Febearing clays.

\section{Conflicts of interest}

There are no conflicts to declare.

\section{Acknowledgements}

We thank M. Fischer and K. Barmettler (Soil Chemistry Group, ETH Zurich) for assistance in the laboratory. We gratefully acknowledge M. Etique (University of Lorraine) for discussions on the synthesis of Fe(II) minerals and M. Siebecker (Texas Tech University) about Wavelet transformation. We acknowledge SOLEIL (proposal no. 20171097) for the provision of synchrotron radiation facilities and thank G. Landrot, E. Fonda and G. Alizon for their support during the synchrotron measurements. We are grateful to E. Elzinga (Rutgers University) for sharing with us the reference XAS spectra of $\mathrm{Fe}(\mathrm{OH})_{2}$ and nikischerite, T. Borch (Colorado State University) the XAS spectra of chloride green rust and A. Zitolo (SOLEIL) for the XAS spectra of aqueous $\mathrm{Fe}^{2+}$ and $\mathrm{Fe}^{3+}$. This research was funded by the Swiss National Science Foundation (grant no. 200021_156392).

\section{References}

1 P. Refait, L. Simon and J. M. R. Genin, Reduction of $\mathrm{SeO}_{4}{ }^{2-}$ anions and anoxic formation of iron(II)-iron(III) hydroxy selenate green rust, Environ. Sci. Technol., 2000, 34, 819-825.

2 V. Badaut, M. L. Schlegel, M. Descostes and G. Moutiers, In situ time-resolved X-ray near-edge absorption spectroscopy of selenite reduction by siderite, Environ. Sci. Technol., 2012, 46, 10820-10826.

3 J. Jonsson and D. M. Sherman, Sorption of As(III) and As(V) to siderite, green rust (fougerite) and magnetite: Implications for arsenic release in anoxic groundwaters, Chem. Geol., 2008, 255, 173-181.

4 S. Sengupta, P. K. Mukherjee, T. Pal and S. Shome, Nature and origin of arsenic carriers in shallow aquifer sediments of Bengal Delta, India, Environ. Geol., 2004, 45, 1071-1081.

5 T. Pal and P. K. Mukherjee, 'Orange sand' - A geological solution for arsenic pollution in Bengal delta, Curr. Sci., 2008, 94, 31-33.

6 W. L. Lindsay and A. P. Schwab, The chemistry of iron in soils and its availability to plants, J. Plant Nutr., 1982, 5, 821-840.

7 W. Stumm and B. Sulzberger, The cycling of iron in natural environments - Considerations based on laboratory studies of heterogeneous redox processes, Geochim. Cosmochim. Acta, 1992, 56, 3233-3257.

8 D. L. Sparks, Environmental soil chemistry, Academic Press, San Diego, 1995.

9 M. H. Bradbury and B. Baeyens, Modelling the sorption of Mn(II), Co(II), Ni(II), Zn(II), Cd(II), Eu(III), Am(III), $\mathrm{Sn}(\mathrm{IV}), \mathrm{Th}(\mathrm{IV}), \mathrm{Np}(\mathrm{V})$ and U(VI) on montmorillonite: Linear free energy relationships and estimates of surface binding constants for some selected heavy metals and actinides, Geochim. Cosmochim. Acta, 2005, 69, 875-892.
10 D. Soltermann, M. Marques Fernandes, B. Baeyens, J. MiehéBrendlé and R. Dähn, Competitive Fe(II)-Zn(II) uptake on a synthetic montmorillonite, Environ. Sci. Technol., 2014, 48, 190-198.

11 J. B. Dixon, S. B. Weed and R. C. Dinauer, Minerals in soil environments, Soil Science Society of America, Madison, Wis., USA, 2nd edn, 1989.

12 F. Favre, J. W. Stucki and P. Boivin, Redox properties of structural $\mathrm{Fe}$ in ferruginous smectite. A discussion of the standard potential and its environmental implications, Clays Clay Miner., 2006, 54, 466-472.

13 A. Neumann, T. L. Olson and M. M. Scherer, Spectroscopic evidence for $\mathrm{Fe}(\mathrm{II})-\mathrm{Fe}(\mathrm{III})$ electron transfer at clay mineral edge and basal sites, Environ. Sci. Technol., 2013, 47, 69696977.

14 A. Géhin, J.-M. Grenèche, C. Tournassat, J. Brendléd, D. G. Rancourt and L. Charlet, Reversible surface-sorptioninduced electron-transfer oxidation of $\mathrm{Fe}(\mathrm{II})$ at reactive sites on a synthetic clay mineral, Geochim. Cosmochim. Acta, 2007, 71, 863-876.

15 M. V. Schaefer, C. A. Gorski and M. M. Scherer, Spectroscopic evidence for interfacial Fe(II)-Fe(III) electron transfer in a clay mineral, Environ. Sci. Technol., 2011, 45, 540-545.

16 C. A. Gorski, M. Aeschbacher, D. Soltermann, A. Voegelin, B. Baeyens, M. Marques Fernandes, T. B. Hofstetter and M. Sander, Redox properties of structural $\mathrm{Fe}$ in clay minerals. 1. Electrochemical quantification of electrondonating and -accepting capacities of smectites, Environ. Sci. Technol., 2012, 46, 9360-9368.

17 C. A. Gorski, L. Klupfel, A. Voegelin, M. Sander and T. B. Hofstetter, Redox properties of structural Fe in clay minerals. 2. Electrochemical and spectroscopic characterization of electron transfer irreversibility in ferruginous smectite, SWa-1, Environ. Sci. Technol., 2012, 46, 9369-9377.

18 C. A. Gorski, L. E. Klupfel, A. Voegelin, M. Sander and T. B. Hofstetter, Redox properties of structural Fe in clay minerals: 3. Relationships between smectite redox and structural properties, Environ. Sci. Technol., 2013, 47, 13477-13485.

19 A. M. Jones, C. A. Murphy, T. D. Waite and R. N. Collins, Fe(II) interactions with smectites: Temporal changes in redox reactivity and the formation of green rust, Environ. Sci. Technol., 2017, 51, 12573-12582.

20 T. B. Hofstetter, R. P. Schwarzenbach and S. B. Haderlein, Reactivity of $\mathrm{Fe}(\mathrm{II})$ species associated with clay minerals, Environ. Sci. Technol., 2003, 37, 519-528.

21 Y. Zhu and E. J. Elzinga, Formation of layered Fe(II)hydroxides during $\mathrm{Fe}(\mathrm{II})$ sorption onto clay and metaloxide substrates, Environ. Sci. Technol., 2014, 48, 4937-4945.

22 T. Huynh, A. R. Tong, B. Singh and B. J. Kennedy, Cdsubstituted goethites - A structural investigation by synchrotron X-ray diffraction, Clays Clay Miner., 2003, 51, 397-402.

23 L. N. Moyes, R. H. Parkman, J. M. Charnock, D. J. Vaughan, F. R. Livens, C. R. Hughes and A. Braithwaite, Uranium 
uptake from aqueous solution by interaction with goethite, lepidocrocite, muscovite, and mackinawite: An X-ray absorption spectroscopy study, Environ. Sci. Technol., 2000, 34, 1062-1068.

24 G. Ona-Nguema, G. Morin, F. Juillot, G. Calas and G. E. Brown, EXAFS analysis of arsenite adsorption onto two-line ferrihydrite, hematite, goethite, and lepidocrocite, Environ. Sci. Technol., 2005, 39, 9147-9155.

25 X. W. Xu, C. Chen, P. Wang, R. Kretzschmar and F. J. Zhao, Control of arsenic mobilization in paddy soils by manganese and iron oxides, Environ. Pollut., 2017, 231, 37-47.

26 K. Ehlert, C. Mikutta and R. Kretzschmar, Impact of birnessite on arsenic and iron speciation during microbial reduction of arsenic-bearing ferrihydrite, Environ. Sci. Technol., 2014, 48, 11320-11329.

$27 \mathrm{U}$. Schwertmann and R. M. Cornell, Iron oxides in the laboratory:preparation and characterization, Wiley-VCH, Weinheim, New York, 2nd completely rev. and extended edn, 2000.

28 J. M. R. Génin, R. Aïssa, A. Géhin, M. Abdelmoula, O. Benali, V. Ernstsen, G. Ona-Nguema, C. Upadhyay and C. Ruby, Fougerite and FeII-III hydroxycarbonate green rust; ordering deprotonation and/or cation substitution; structure of hydrotalcite-like compounds and mythic ferrosic hydroxide $\mathrm{Fe}(\mathrm{OH})^{(2+\mathrm{x})}$, Solid State Sci., 2005, 7, 545572.

29 J. W. Stucki, B. A. Goodman and U. Schwertmann, Iron in soils and clay minerals, D. Reidel, Dordrecht, 1988.

30 D. Soltermann, M. Marques Fernandes, B. Baeyens, R. Dähn, J. Miehé-Brendlé, B. Wehrli and M. H. Bradbury, Fe(II) sorption on a synthetic montmorillonite. A combined macroscopic and spectroscopic study, Environ. Sci. Technol., 2013, 47, 6978-6986.

31 K. Lagarec and D. G. Rancourt, Recoil - Mössbauer spectral analysis software for Windows., University of Ottawa, Ottawa, 1998.

32 D. G. Rancourt and J. Y. Ping, Voigt-based methods for arbitrary-shape static hyperfine parameter distributions in mossbauer-spectroscopy, Nucl. Instrum. Methods Phys. Res., Sect. B, 1991, 58, 85-97.

33 H. Funke, A. C. Scheinost and M. Chukalina, Wavelet analysis of extended x-ray absorption fine structure data, Phys. Rev. B: Condens. Matter Mater. Phys., 2005, 71, 094110.

34 Y. Zhu, J. J. Liu, O. Goswami, A. A. Rouff and E. J. Elzinga, Effects of humic substances on Fe(II) sorption onto aluminum oxide and clay, Geochem. Trans., 2018, 19, 3.

35 D. L. Sparks, Kinetics of Ionic Reactions in Clay-Minerals and Soils, Adv. Agron., 1985, 38, 231-266.

36 A. M. Scheidegger, G. M. Lamble and D. L. Sparks, Spectroscopic evidence for the formation of mixed-cation hydroxide phases upon metal sorption on clays and aluminum oxides, J. Colloid Interface Sci., 1997, 186, 118128.

37 A. C. Scheinost, R. G. Ford and D. L. Sparks, The role of Al in the formation of secondary Ni precipitates on pyrophyllite, gibbsite, talc, and amorphous silica: A DRS study, Geochim. Cosmochim. Acta, 1999, 63, 3193-3203.
38 E. J. Elzinga and D. L. Sparks, Nickel sorption mechanisms in a pyrophyllite-montmorillonite mixture, $J$. Colloid Interface Sci., 1999, 213, 506-512.

39 A. M. Scheidegger, D. G. Strawn, G. M. Lamble and D. L. Sparks, The kinetics of mixed Ni-Al hydroxide formation on clay and aluminum oxide minerals: A timeresolved XAFS study, Geochim. Cosmochim. Acta, 1998, 62, 2233-2245.

40 A. M. Scheidegger, G. M. Lamble and D. L. Sparks, Investigation of $\mathrm{Ni}$ sorption on pyrophyllite: An XAFS study, Environ. Sci. Technol., 1996, 30, 548-554.

41 A. C. Scheinost and D. L. Sparks, Formation of layered singleand double-metal hydroxide precipitates at the mineral/ water interface: A multiple-scattering XAFS analysis, J.Colloid Interface Sci., 2000, 223, 167-178.

42 W. Li, K. J. T. Livi, W. Q. Xu, M. G. Siebecker, Y. J. Wang, B. L. Phillips and D. L. Sparks, Formation of crystalline ZnAl layered double hydroxide precipitates on gammaalumina: The role of mineral dissolution, Environ. Sci. Technol., 2012, 46, 11670-11677.

43 A. N. Starcher, E. J. Elzinga and D. L. Sparks, Formation of a mixed $\mathrm{Fe}(\mathrm{II})-\mathrm{Zn}-\mathrm{Al}$ layered hydroxide: Effects of $\mathrm{Zn} \mathrm{co-}$ sorption on $\mathrm{Fe}(\mathrm{II})$ layered hydroxide formation and kinetics, Chem. Geol., 2017, 464, 46-56.

44 A. N. Starcher, W. Li, R. K. Kukkadapu, E. J. Elzinga and D. L. Sparks, Fe(II) sorption on pyrophyllite: Effect of structural Fe(III) (impurity) in pyrophyllite on nature of layered double hydroxide (LDH) secondary mineral formation, Chem. Geol., 2016, 439, 152-160.

45 J. M. R. Génin, G. Bourrie, F. Trolard, M. Abdelmoula, A. Jaffrezic, P. Refait, V. Maitre, B. Humbert and A. Herbillon, Thermodynamic equilibria in aqueous suspensions of synthetic and natural $\mathrm{Fe}(\mathrm{II})$-Fe(III) green rusts: Occurrences of the mineral in hydromorphic soils, Environ. Sci. Technol., 1998, 32, 1058-1068.

46 P. Refait and J. M. R. Genin, Mechanisms of oxidation of $\mathrm{Ni}(\mathrm{II})-\mathrm{Fe}(\mathrm{II})$ hydroxides in chloride-containing aqueous media: Role of the pyroaurite-type Ni-Fe hydroxychlorides, Clay Miner., 1997, 32, 597-613.

47 S. C. F. Auyeung, G. Denes, J. E. Greedan, D. R. Eaton and T. Birchall, A novel synthetic route to iron trihydroxide, $\mathrm{Fe}(\mathrm{OH})_{3}$ - characterization and magnetic-properties, Inorg. Chem., 1984, 23, 1513-1517.

48 J. Klausen, S. P. Trober, S. B. Haderlein and R. P. Schwarzenbach, Reduction of substituted nitrobenzenes by $\mathrm{Fe}(\mathrm{II})$ in aqueous mineral suspensions, Environ. Sci. Technol., 1995, 29, 2396-2404.

49 A. Neumann, T. B. Hofstetter, M. Skarpeli-Liati and R. P. Schwarzenbach, Reduction of polychlorinated ethanes and carbon tetrachloride by structural $\mathrm{Fe}(\mathrm{II})$ in smectites, Environ. Sci. Technol., 2009, 43, 4082-4089.

50 T. B. Hofstetter, A. Neumann and R. P. Schwarzenbach, Reduction of nitroaromatic compounds by $\mathrm{Fe}(\mathrm{II})$ species associated with iron-rich smectites, Environ. Sci. Technol, 2006, 40, 235-242.

51 D. M. C. Huminicki and F. C. Hawthorne, The crystal structure of nikischerite, $\mathrm{Na} \quad \mathrm{Fe}^{2+}{ }_{6} \mathrm{Al}_{3}\left(\mathrm{SO}_{4}\right)_{2} \quad(\mathrm{OH})_{18}$ 
$\left(\mathrm{H}_{2} \mathrm{O}\right)_{12}$, a mineral of the shigaite group, Can. Mineral., 2003, 41, 79-82.

52 A. Voegelin, A. C. Scheinost, K. Buhlmann, K. Barmettler and R. Kretzschmar, Slow formation and dissolution of $\mathrm{Zn}$ precipitates in soil - A combined column-transport and XAFS study, Environ. Sci. Technol., 2002, 36, 3749-3754.

53 O. Jacquat, A. Voegelin, A. Villard, M. A. Marcus and R. Kretzschmar, Formation of Zn-rich phyllosilicate, Znlayered double hydroxide and hydrozincite in contaminated calcareous soils, Geochim. Cosmochim. Acta, 2008, 72, 5037-5054.

54 L. Bhattacharya and E. J. Elzinga, A comparison of the solubility products of layered $\mathrm{Me}(\mathrm{II})$-Al(III) hydroxides based on sorption studies with $\mathrm{Ni}(\mathrm{II}), \mathrm{Zn}(\mathrm{II}), \mathrm{Co}(\mathrm{II}), \mathrm{Fe}(\mathrm{II})$, and Mn(II), Soil Syst., 2018, 2, 20.

55 S. D. Kelly, B. Hesterdberg and B. Ravel, in Methods of Soil Analysis Part 5-Mineralogical Methods, SSSA Book Ser. 5.5. $S S S A$, ed. L. R. D. A. L. Ulery, Madison, WI, 2008, pp. 387463, DOI: 10.2136/sssabookser5.5.c14.

56 F. Trolard, G. Bourrie, M. Abdelmoula, P. Refait and F. Feder, Fougerite, a new mineral of the pyroaurite-iowaite group: Description and crystal structure, Clays Clay Miner., 2007, 55, 323-334.

57 H. Shirozu and S. W. Bailey, Chlorite Polytypism .III. crystal structure of an orthohexagonal iron chlorite, Am. Mineral., 1965, 50, 868-885.

58 R. Dähn, B. Baeyens and M. H. Bradbury, Investigation of the different binding edge sites for $\mathrm{Zn}$ on montmorillonite using P-EXAFS - The strong/weak site concept in the 2SPNE SC/CE sorption model, Geochim. Cosmochim. Acta, 2011, 75, 51545168.

59 R. Dähn, A. M. Scheidegger, A. Manceau, M. L. Schlegel, B. Baeyens, M. H. Bradbury and M. Morales, Neoformation of Ni phyllosilicate upon Ni uptake on montmorillonite: A kinetics study by powder and polarized extended X-ray absorption fine structure spectroscopy, Geochim. Cosmochim. Acta, 2002, 66, 2335-2347.

60 A. Manceau, D. Chateigner and W. P. Gates, Polarized EXAFS, distance-valence least-squares modeling (DVLS), and quantitative texture analysis approaches to the structural refinement of Garfield nontronite, Phys. Chem. Miner., 1998, 25, 347-365.

61 A. Manceau and M. L. Schlegel, Texture effect on polarized EXAFS amplitude, Phys. Chem. Miner., 2001, 28, 52-56.

62 A. Manceau, D. Bonnin, P. Kaiser and C. Fretigny, Polarized EXAFS of Biotite and Chlorite, Phys. Chem. Miner., 1988, 16, 180-185.

63 A. Manceau, Critical evaluation of the revised akdalaite model for ferrihydrite, Am. Mineral., 2011, 96, 521-533.

64 A. P. Zhukhlistov, Crystal structure of lepidocrocite $\mathrm{FeO}(\mathrm{OH})$ from the electron-diffractometry data, Crystallogr. Rep., 2001, 46, 730-733.
65 L. L. Baker and D. G. Strawn, Fe K-edge XAFS spectra of phyllosilicates of varying crystallinity, Phys. Chem. Miner., 2012, 39, 675-684.

66 A. Voegelin, R. Kaegi, J. Frommer, D. Vantelon and S. J. Hug, Effect of phosphate, silicate, and $\mathrm{Ca}$ on $\mathrm{Fe}(\mathrm{III})$-precipitates formed in aerated $\mathrm{Fe}(\mathrm{II})$ - and As(III)-containing water studied by X-ray absorption spectroscopy, Geochim. Cosmochim. Acta, 2010, 74, 164-186.

67 D. E. Latta, A. Neumann, W. A. P. J. Premaratne and M. M. Scherer, Fe(II)-Fe(III) electron transfer in a clay mineral with low Fe content, ACS Earth and Space Chem, 2017, 1, 197-208.

68 A. C. Senn, R. Kaegi, S. J. Hug, J. G. Hering, S. Mangold and A. Voegelin, Composition and structure of $\mathrm{Fe}(\mathrm{III})$ precipitates formed by $\mathrm{Fe}(\mathrm{II})$ oxidation in water at nearneutral pH: Interdependent effects of phosphate, silicate and Ca, Geochim. Cosmochim. Acta, 2015, 162, 220-246.

69 R. M. Cornell and U. Schwertmann, The iron oxides : structure, properties, reactions, occurrences, and uses, Wiley$\mathrm{VCH}$, Weinheim, New York, 2nd, completely rev. and extended edn, 2003.

70 P. Gütlich, E. Bill and A. X. Trautwein, Mossbauer Spectroscopy and Transition Metal Chemistry: Fundamentals and Applications, Springer, 2011.

71 L. T. Kuhn, K. Lefmann, C. R. H. Bahl, S. N. Ancona, P. A. Lindgard, C. Frandsen, D. E. Madsen and S. Morup, Neutron study of magnetic excitations in 8-nm alpha- $\mathrm{Fe}_{2} \mathrm{O}_{3}$ nanoparticles, Phys. Rev. B: Condens. Matter Mater. Phys., 2006, 74, 184406.

72 C. M. Chen, R. Kukkadapu and D. L. Sparks, Influence of coprecipitated organic matter on Fe-(aq)(2+)-catalyzed transformation of ferrihydrite: implications for carbon dynamics, Environ. Sci. Technol., 2015, 49, 10927-10936.

73 A. M. Jones, R. N. Collins, J. Rose and T. D. Waite, The effect of silica and natural organic matter on the Fe(II)-catalysed transformation and reactivity of Fe(III) minerals, Geochim. Cosmochim. Acta, 2009, 73, 4409-4422.

74 C. M. Hansel, S. G. Benner and S. Fendorf, Competing Fe(II)induced mineralization pathways of ferrihydrite, Environ. Sci. Technol., 2005, 39, 7147-7153.

75 C. M. Hansel, S. G. Benner, J. Neiss, A. Dohnalkova, R. K. Kukkadapu and S. Fendorf, Secondary mineralization pathways induced by dissimilatory iron reduction of ferrihydrite under advective flow, Geochim. Cosmochim. Acta, 2003, 67, 2977-2992.

$76 \mathrm{~J}$. W. Gruner, The composition and structure of minnesotaite, a common iron silicare in iron formations, Am. Mineral., 1944, 29, 363-372.

77 C. Mikutta, X-ray absorption spectroscopy study on the effect of hydroxybenzoic acids on the formation and structure of ferrihydrite, Geochim. Cosmochim. Acta, 2011, 75, 5122-5139. 